\title{
Soaking Up the Sun: \\ The Role of Sunshine in the Production of Infant Health
}

\author{
Jennifer Trudeau ${ }^{\mathrm{a}}$, Karen Smith Conway ${ }^{\mathrm{b} *}$, \\ and Andrea Kutinova Menclova ${ }^{\mathrm{c}}$
}

\begin{abstract}
This research explores the role of sunshine in birth outcomes production, focusing primarily on fetal growth. The most obvious mechanism is through Vitamin D absorption, which could explain racial disparities in birth weight because skin pigmentation inhibits this process. However, sunshine may have additional effects and is closely connected to environmental factors, season of birth, and geography. Combining daily weather data with 1989-2004 birth outcomes from the Natality Detail Files, we estimate sunshine's effects in a range of models that disentangle these confounding factors. Our results suggest that sunshine has a positive but diminishing effect on birth weight for Blacks and a negative effect for Whites. These findings are consistent with the presumed positive but diminishing effects of sunshine via Vitamin D balanced against the possible negative effects via folic acid depletion and immune system impairment. The estimated magnitudes are in line with those found for other key factors such as feeding programs and air pollution and suggest that sunshine's effects explain a nontrivial portion of racial differences in birth weight. Implications include possible interventions (vitamin supplementation for Blacks, sun avoidance for Whites) and the need to include sunshine as a potentially important factor in birth outcomes research. (JEL Codes: I1, Q5)
\end{abstract}

Keywords: infant health, weather, sunshine, racial disparities

Acknowledgements: We would like to thank Vladimir Mencl from BlueFern Computing Services at the University of Canterbury for computing assistance and David Niles for his research assistance. This paper has also benefited from the comments of Christian Asseburg, David Bradford, Dhaval Dave, Donka Mirtcheva, Nancy Reichman, Chris Ruhm and participants in our sessions at the Eastern Economic Association, iHEA and Southern Economic Association Meetings.

a Sacred Heart University, Department of Business Economics, 5151 Park Avenue, Fairfield, CT 06611, USA. Email: trudeauj@ sacredheart.edu.

${ }^{\mathrm{b}}$ University of New Hampshire, Department of Economics, 10 Garrison Avenue, Durham, NH 03824, USA. Email: karen.conway@unh.edu. Phone: (603) 862-3386.

${ }^{c}$ University of Canterbury, Department of Economics and Finance, Private Bag 4800, Christchurch, New Zealand. E-mail: andrea.menclova@ canterbury.ac.nz.

* Corresponding author 


\section{INTRODUCTION}

This research investigates the effects of a heretofore unexplored factor - sunshine - on the production of infant health and the implications for racial disparities in particular. The most obvious effect of sunshine is its role in the production of Vitamin D. Because skin pigmentation inhibits Vitamin D production from the sun, this effect likely differs by race and could help explain the well-documented racial gap in birth outcomes (e.g., Goldenberg et al. 1996, Dubay et al. 2001, Lhila and Long 2012). Vitamin D deficiency is fairly widespread, and it is especially prominent among Blacks, including pregnant women. ${ }^{1}$ Medical research on the effects of Vitamin D on birth outcomes and its possible link to racial disparities has exploded in recent years, but the evidence has been mixed and limited in scope..$^{2}$ In addition, recent medical research suggests that sun exposure may have negative direct effects as well, as UV radiation is associated with a depletion of folic acid - a key nutrient before and during pregnancy - and impairment of the immune system (Fukuwatari et al. 2009, Norval 2011, Norval and Halliday 2011). The effect of sunshine on birth outcomes is thus both theoretically ambiguous and empirically unresolved and likely differs by race.

Our research contributes to the literature by incorporating sunshine and temperature into a standard infant health production function, which we then estimate using the Natality Detailed Files from 1989-2004 and daily meteorological data from NASA's Surface Meteorology and Solar Energy: Daily Averaged Data. Our empirical analyses address possibly confounding factors such as locational and seasonal effects, selection into pregnancy and other environmental

\footnotetext{
${ }^{1}$ For instance, one study found Vitamin D insufficiency among 92.2\% of non-Hispanic Black pregnant women, compared to $49.1 \%$ of non-Hispanic White pregnant women (Bodnar et al. 2010). See also Dror and Allen (2010, Table 1) for a summary of studies of the prevalence of Vitamin D deficiency during pregnancy for different groups. ${ }^{2}$ Recent work includes Bodnar and Simhan (2010), Brannon and Picciano (2011), Dror and Allen (2010), Lapillonne (2010), Lewis et al. (2010), Ponsoby et al. (2010), and Grayson and Hewison (2011) and typically deals with very small samples of women in one geographic location and/or observing them at only one point during their pregnancy. Evidence from Randomized Control Trials (RCTs) is notably lacking (Brannon and Picciano 2011); Wagner et al. (2013) is the most recent RCT to our knowledge.
} 
factors such as air pollution. We also explore many measures of weather, including those that allow for differing effects by point in pregnancy and weekends versus weekdays and for more complicated and nonlinear relationships in sunshine and temperature. Our results suggest a negative effect of sunshine on birth weight among Whites (presumably through folic acid depletion or immune system impairment) and a positive effect - at least up to a point - among Blacks (whose Vitamin D deficiency is widely established). The sizes of these effects are similar to those found for other interventions and are nontrivial: among full-term births, moving from the $1^{\text {st }}$ decile of insolation to the $10^{\text {th }}$ is estimated to close the racial birth weight gap by about 26 grams, representing approximately $12 \%$ of the gap observed in our data.

Our findings have implications for other economic studies of infant health. Sun exposure is strongly correlated with geography and season of birth and therefore may help explain the strong differences in birth outcomes observed (e.g., Cullen et al. 2012 and Buckles and Hungerman 2013). Likewise, a growing body of economics research has found environmental factors such as air pollution, natural disasters and temperature - all of which are correlated with sunshine - to have an impact on birth outcomes (e.g., Deschenes et al. 2009, Currie et al. 2009, Simeonova 2011, Andalón et al. 2014). Yet, none have considered the effects of sunshine. Even the effects of policies designed to improve birth outcomes have potential, albeit indirect, connections to sunshine. Feeding programs such as Women, Infants and Children (WIC) and food stamps (SNAP) emphasize folic acid and calcium-rich foods (which aid in the absorption of Vitamin D). These nutrients are potentially affected by sun exposure, which could help explain the stronger effects observed for Blacks (e.g., Brien and Swann 2001, Almond et al. 2011) and suggests seasonal and geographic differences as well. The American Congress of Obstetricians and Gynecologists (ACOG) changed its recommended amounts for Vitamin D in 
both 1992 and 2002. ${ }^{3}$ This coincides with the Medicaid and State Children's Health Insurance

Program expansions, respectively, and suggests that Vitamin D deficiency - and perhaps the efficacy of prenatal care in that regard - was changing at the same time and in a way that differs by race and geographic location.

Overall, our estimated effects of sunshine, while small, are commensurate with and may even help explain those found for participation in SNAP and WIC, and for environmental factors such as air pollution and extreme weather events. Moreover, given that we find sunshine to have differential effects by race, our results help explain a nontrivial portion of the racial gap in birth weight, which is both biologically plausible and suggestive of new ways to reduce racial disparities in health outcomes.

\section{PAST RESEARCH}

Our research combines the clinical evidence on the relationships between Vitamin D, sunshine, race and health with empirical methods from health economics research that are designed to isolate causal effects of environmental factors from other confounding factors and behavioral responses. As such, both types of research are relevant and are discussed here.

\section{II.A. Relevant Health Economics Research}

Economic investigation of sun exposure as a determinant of health has been very limited. Carson $(2008,2009,2010)$ analyzes heights of Black, White, and Hispanic prisoners in the

\footnotetext{
${ }^{3}$ These changes coincided with updated sources for dietary guidelines. In 1992, one recommended level was given for all pregnant women, whereas in 1983 and 1988 the levels had been higher for young women (age < 23). In 2002, the (reduced) level was now based on 'Adequate Intake' (AI) instead of a 'Recommended Daily Dietary Allowance' (RDA), a switch made "if insufficient evidence is available to determine an RDA" (Table 4-2, p. 91, ACOG 2002). While the reports do not provide an explicit reason for these changes, Vieth (2007) makes clear that Vitamin D toxicity, in particular hypercalcemia, has been the over-riding concern in setting these guidelines. This Vitamin D toxicity concern also appears in every ACOG volume. The link to sun exposure is mentioned first in 1992. It is mentioned again in 2002 and 2007 but only as a possible source of Vitamin D along with certain food items.
} 
nineteenth- and early twentieth-century US using recent NASA insolation data - the same measure we use - to proxy for sun exposure during that period. ${ }^{4}$ Like birth weight in birth outcomes research, height is a widely used measure of living standards in economic history (Carson 2009). Emphasizing racial/skin pigmentation differences in Vitamin D synthesis, Carson $(2008,2009)$ investigates the degree to which insolation explains observed racial differences in height in the nineteenth century, controlling for confounding factors such as age, birth cohort, nativity and occupation. Carson (2009) finds nonlinear effects of insolation on height that are larger for Blacks than for Whites or Mulattos (Table 3, p. 155). Using a BlinderOaxaca decomposition to identify the sources of height differences, he concludes that BlackWhite differences are mostly due to unobservables, but that "the majority of the stature differential due to observable characteristics is associated with insolation" (p. 156). Moreover, more than $50 \%$ of the $2.21 \mathrm{~cm}$ height difference between Black individuals born in Africa versus those born in the US is attributable to insolation (sun exposure).

More recently, Wernerfelt et al. (2014) investigate the impacts of sun exposure during pregnancy on later-life asthma of the offspring and find significant beneficial impacts of sunshine during the second trimester. The study unfortunately does not stratify by race, hindering any conclusions about the role of sunshine in explaining racial health discrepancies.

Economic studies of birth outcomes most relevant to our paper are those that investigate the effects of extreme weather (Deschenes et al. 2009, Deschenes and Moretti 2009, Simeonova 2011, Currie and Rossin-Slater 2013, Andalón et al. 2014) and season of birth (Kestenbaum 1987, Lokshin and Radaykin 2012, Buckles and Hungerman 2013). Research on extreme weather is often motivated by and linked to the welfare costs of climate change and focuses on

\footnotetext{
${ }^{4}$ Insolation is the solar energy which reaches the Earth's surface in a given area and time. Note that Carson's measure of sun exposure lacks any time variation; in fact, he uses a current average value to proxy for the conditions at each location during his period of study.
} 
controlling for confounding factors. Such research has found that exposure to extremely hot or cold temperatures ${ }^{5}$ or natural disasters (storms, floods, etc.) has a detrimental effect on birth outcomes, but has provided little evidence on the causal mechanisms at work and has not considered possible sun exposure as a factor. ${ }^{6}$

Season-of-birth research often includes weather differences as one of several possible reasons for seasonal differences in birth outcomes, but has not explored the link directly. Rather, it has used these seasonal differences to question the validity of season of birth as an instrumental variable (Buckles and Hungerman 2013) and/or explore the validity of alternative explanations (Lokshin and Radaykin 2012). Endogenous self-selection is a key explanation as women may plan their pregnancies with regular weather or other seasonal patterns in mind (e.g., holidays, vacations, school year; see Buckles and Hungerman 2013, Basso et al. 1995). The falsification testing we conduct reveals the importance of this selection and that it may be location-specific a nuance that is sometimes overlooked but is accounted for in our models in a manner similar to Buckles and Hungerman (2013).

Another relevant line of economic research explores the effects of air pollutants on infant health. Air pollution seems likely to play a similar role within an infant health production model and suffer from similar confounding effects as insolation. The two factors may be directly related as well, as ozone may impede solar insolation (Webb and Engelsen 2006) and sunshine aids in the production of ozone from auto emissions (Knittel et al. 2011). Currie (2011) provides

\footnotetext{
${ }^{5}$ Basu et al. (2010) is an especially careful epidemiological study of birth outcomes that finds high temperatures increase the risk of preterm birth. Deschenes and Moretti (2009) focus on the effects on mortality (across age groups) of both hot and cold temperatures. Their evidence suggests a 'harvesting' effect for hot temperatures, whereby death rates actually fall in the days following a heat wave, and a more persistent effect of extremely cold temperatures. See also Deschenes (2012) for a review of research into the health effects of temperature.

${ }^{6}$ Aizer et al. (2012) provides evidence for one potential mechanism - maternal stress -via maternal blood cortisol levels. Sun exposure may play a role here too as clinical evidence suggests a relationship between Vitamin D status and mental health outcomes such as depression and stress (Premkumar et al. 2013, Cassidy-Bushrow et al. 2012., Ganji et al. 2010, Humble 2010).
} 
a summary of confounding factors in estimating the causal effects of air pollution, including its correlation with unobserved factors such as economic activity and mothers' decisions to locate in a polluted area. While changes in sun exposure over time seem less likely to suffer from these confounding effects, especially during our sample period when the possible benefits of Vitamin D were little known, our results must be interpreted with similar caveats in mind.

Sun exposure is correlated with temperature, season of birth and air pollution and yet has been excluded as a factor in past research. Our study therefore provides evidence for the possible effects of this omission. We also borrow from previous literature in devising empirical strategies to control for these other environmental factors and other confounders in our attempt to identify the causal effect of sun exposure. Finally, as the clinical research discussed next reveals, sunshine's effects manifest via nutrients and thus its effects also have implications for racial differences in the efficacy of feeding programs and prenatal care.

\section{II.B. Clinical Evidence of Possible Effects of Sunshine on Birth Outcomes}

To our knowledge, the effects of sunshine, as well as its possible conduits Vitamin D and folic acid, on birth outcomes have only been studied in other disciplines, primarily clinical research. The most obvious and heavily emphasized direct health effect of sun exposure is via Vitamin D absorption (e.g., Holick 2002, 2007). The role of Vitamin D during pregnancy has been explored in numerous studies, resulting in a large number of review articles in just the last few years (e.g., Bodnar and Simhan 2010, Brannon and Picciano 2011, Dror and Allen 2010, Lapillonne 2010, Lewis et al. 2010, Ponsoby et al. 2010, Grayson and Hewison 2011). These reviews typically discuss the determinants and prevalence of Vitamin D deficiency among pregnant women and then proceed to the possible biological mechanisms and empirical evidence regarding the effects of Vitamin D on a host of pregnancy and birth outcomes. The main 
conclusions from these reviews are similar and so we discuss them as a group. The evidence of sun exposure affecting health via Vitamin D production is summarized with three links:

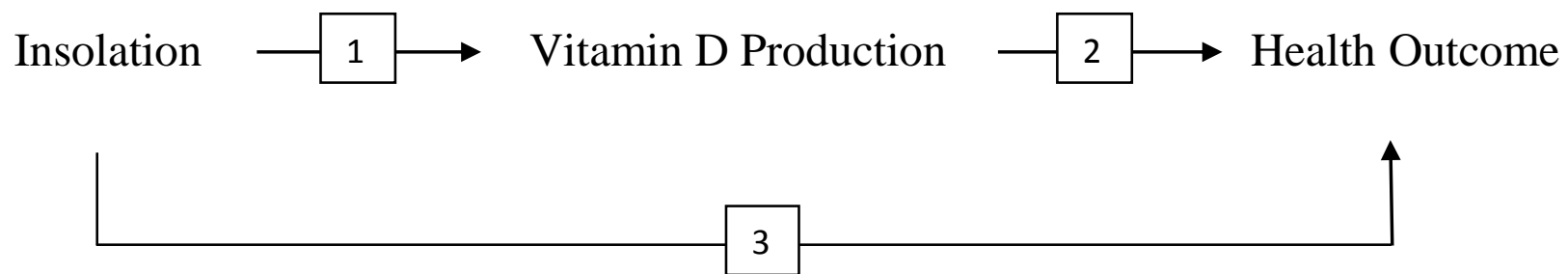

Vitamin D is a fat soluble seco-sterol that acts as an agent in the absorption and transport of calcium in the body. It appears in two forms: 1) ergocalciferol or 'Vitamin $\mathrm{D}_{2}$,' which is acquired via ingestion of certain foods (fish, dairy), and 2) cholecalciferol or 'Vitamin $\mathrm{D}_{3}$,' which is produced in the body via exposure to UV-B radiation and photosynthesis within the skin - i.e., link \#1 above (CDC 2008). While both sources are currently available as supplements for overthe-counter consumption, during the time of our study supplementation was very limited and health policy was primarily driven by concerns about Vitamin D toxicity rather than deficiency (Vieth 2007). ${ }^{7}$ Both mechanisms, diet and sun exposure, may differ by race (Arab et al. 2003, Swamy et al. 2011). Studies show that up to $70 \%$ of Blacks have lactase non-persistence, leaving them susceptible to symptoms of lactose intolerance (Byers and Savaiano 2005) which in turn makes them less likely to consume dairy (Vitamin $\mathrm{D}_{2}$ rich) foods. Likewise, Vitamin $\mathrm{D}_{3}$ is not photosynthesized consistently across different concentrations of skin pigmentation and is inhibited by darker skin. ${ }^{8}$

\footnotetext{
${ }^{7}$ Supplements for Vitamin $\mathrm{D}_{3}$ (produced via sun exposure) and Vitamin $\mathrm{D}_{2}$ (via diet) received FDA approval in 2003 and 2009, respectively (FDA 2011). See footnote 3 for more on toxicity concerns.

${ }^{8}$ As discussed in Jablonski (2004), Rajakumar and Thomas (2005) and Borradale (2013), differences in skin pigmentation arose out of an evolutionary need to balance the favorable and adverse effects of sun exposure. Skin pigmentation protects the body from harmful UV radiation but inhibits the production of Vitamin D. Therefore, humans living in latitudes farther from the equator evolved fairer skin than those living closer. With increased mobility, however, these once useful traits have led to Vitamin D insufficiency among dark-skinned individuals living far from the equator.
} 
It is this second mechanism, link \#1 (sun exposure $\rightarrow$ Vitamin D), that is of primary interest here. The empirical evidence is well established (e.g., Mulligan et al. 2010, Bodnar et al. 2007, Reusch et al. 2009, Nesby-O’Dell et al. 2002, Harris and Dawson-Hughes 1998) and yields several key insights. First, the body regulates the amount of Vitamin D acquired, preventing hypervitaminosis D (toxicity) from occurring as a result of sun exposure (Holick 2007). Put simply, one cannot overdose on Vitamin D via sun exposure; in production terms, link \#1 exhibits diminishing marginal returns. Second, UV-B, the catalyst of the photosynthesizing process, is one of the most harmful forms of UV radiation (HPS 2009), and researchers therefore recommend individuals get outdoors for a 'sensible' 5-30 minutes exposure twice a week, during the midday hours when insolation is direct, so that they can reap the benefits of sunshine while spending the least amount of time under the sun (Holick 2007). Third, the distribution of UV-B radiation varies greatly across latitude and season (Godar et al. 2012, Terushkin et al. 2010, Reusch et al. 2009), and factors such as ozone composition reduce the amount of insolation that reaches the Earth's surface. For instance, on a clear day in June and a latitude of 42.5 degrees (e.g., Buffalo, NY) a fair-skinned Caucasian woman can achieve sufficient Vitamin D production in 4 minutes at noon while it takes 19 minutes for a darkskinned woman. In December, the required time increases to 70 minutes for fair skinned women, with duration for dark-skinned women exceeding the length of the day (Webb and Engelsen 2006).

This discrepancy in Vitamin D synthesis helps explain both seasonal and racial disparities in Vitamin D sufficiency - and thus perhaps infant health outcomes, as argued by Fuller (2000) and others. Widespread deficiency and insufficiency of Vitamin D has been found among all groups, but especially among pregnant women and the elderly, and Blacks have an especially 
high prevalence (Ginde et al. 2010, Looker et al. 2011 and above surveys). This situation has led to calls for increasing the recommended Vitamin D dose for pregnant women from the current 400 IUs to as much as 4,000 IUs (Hollis et al. 2011).

Empirical evidence for link \#2 (Vitamin D $\rightarrow$ Birth outcomes) is much weaker. Vitamin D has a half-life of 2-3 weeks (Wolpowitz and Gilchrest 2006), indicating a rapid decay if not replenished. Therefore, measuring sun exposure and other Vitamin D-producing behaviors during pregnancy is likely sufficient to capture a possible relationship. The vast majority of the existing research on Vitamin D and pregnancy outcomes are medical studies which use small samples of pregnant women and Vitamin D levels measured in the blood at one point during pregnancy (e.g., Bodnar et al. 2007, Bodnar et al. 2010, Gale et al. 2008), although some also estimate Vitamin D status on the basis of dietary intake (Mannion et al. 2006, Scholl and Chen 2009). A strong relationship between maternal and fetal Vitamin D blood levels has been established, and plausible biological mechanisms for Vitamin D to affect specific pregnancy outcomes are outlined in several of the more technical reviews (e.g., Mulligan et al. 2010, Dror and Allen 2010, Grayson and Hewison 2011).

These studies reveal that Vitamin D status is associated with fertility, pre-eclampsia, gestational diabetes, bacterial vaginosis, preterm birth, gestational age and mode of birth (csection vs. vaginal), as well as maternal and fetal bone health. The evidence of a relationship with birth weight or fetal size, however, is more mixed. For instance, after first establishing a strong correlation between potential UV-B exposure and maternal Vitamin D blood levels (link \#1), Gale et al. (2008) find no statistically significant effect of maternal Vitamin D on infant size (link \#2). Conversely, Mannion et al. (2006) and Scholl and Chen (2009) find a significant relationship between Vitamin D intake and infant birth weight. Most recently, Gernand et al. 
(2013) use the same data source as Aizer et al. (2012) and find significant effects of maternal Vitamin D blood levels on birth weight and Small for Gestational Age - but only in the first trimester.

Establishing a causal effect of Vitamin D poses several challenges. First, uncertainty remains about the appropriate thresholds for classifying Vitamin D status (Dror and Allen 2010). Second, Vitamin D measured either by maternal blood or dietary intake is likely endogenous and correlated with confounding factors such as ethnicity, weight gain, and other maternal behaviors. ${ }^{9}$ RCT studies avoid these pitfalls, but to our knowledge, Wagner et al. (2013), Hollis et al. (2011), and Yu et al. (2009) are the only ones conducted in developed countries in the last twenty years to study the effects of increased Vitamin D supplementation in pregnancy. All three studies find that Vitamin D blood levels are significantly increased with supplementation but find no statistically significant differences in birth weight and other birth outcomes. Limitations of these studies include small sample sizes (Wagner et al. 2013 has $<300$ observations, Hollis et al. 2011 has < 400, and Yu et al. 2009 has 180) and only one location (South Carolina, a southerly state where Vitamin D deficiency may be less prevalent than in more northern latitudes, in Wagner et al. 2013 and Hollis et al. 2011, and London in Yu et al. 2009).

A few studies investigate link \#3 directly, essentially using potential sun exposure as an instrument for Vitamin D, as suggested by Sayers et al. (2009). Here again, the evidence is mixed and limited. Using data from Northern Ireland, Murray et al. (2000) control for the mean daily number of 'hours of bright sunshine' in each trimester in an effort to explain the seasonality

\footnotetext{
${ }^{9}$ Medical research notes this challenge as well (e.g., Brannon and Picciano 2011). As Dror and Allen (2010, pp. 467-8) note: "Any relationship between maternal vitamin D status and birth weight or size is likely to be obscured by multiple confounding factors including maternal ethnicity, pre-pregnancy BMI, weight gain during pregnancy, gestational diabetes, smoking and parental stature."
} 
of birth weight but conclude it does not alter the seasonal pattern. Conversely, Tustin et al. (2004) find that increased sunlight exposure by New Zealand mothers during the first trimester of gestation has a significantly positive effect on birth weight.

Sun exposure may have other direct effects on health, however. A small recent medical literature suggests that UV radiation may weaken the immune response to several infectious diseases (Norval 2011, Norval and Halliday 2011) and possibly reduce the efficacy of vaccination (Norval and Woods 2011). Furthermore, evidence exists that sunlight exposure may adversely affect pregnant women by lowering their blood folate levels (Fukuwatari et al. 2009, Borradale 2013). Folate is a key nutrient before and during pregnancy as it reduces the incidence of neural tube defects in the infant (Daly et al. 1995). Important for our study, low levels of folate have also been found to increase the risks of preterm birth, low birth weight and fetal growth retardation (see Scholl and Johnson 2000 for a review).

To summarize the 3-link diagram above, link \#1 ( sun $\rightarrow$ Vitamin D) is firmly established but link \#2 (Vitamin $\mathrm{D} \rightarrow$ birth outcomes) has proven more challenging, in part because of the endogeneity of observed Vitamin D status. Studies of the reduced form effect (link \#3, sun $\rightarrow$ birth outcomes) have produced mixed results and are confounded by evidence that sunshine may have other direct effects on infant health as well. Their more limited data also preclude controlling for confounding effects such as seasonal selection into pregnancy and unobservable geographic factors. Our richer data and empirical methods address these shortcomings.

\section{DATA}

Isolating the health effects of sunshine from other seasonal, geographic and selection factors requires data on birth outcomes, maternal characteristics, and weather over a long period of time. Our data on maternal health characteristics and inputs as well as infant health outcomes 
are from the Natality Detail Files (NDF) for 1989-2004. ${ }^{10}$ The Centers for Disease Control and Prevention (CDC) publicly provide data for counties of populations greater than 100,000 with 100 or more reported births per year. The NDF supplies infant indicators such as birth weight, gender, gestation and maternal characteristics such as age, education and marital status; health inputs/behaviors including smoking, prenatal care, and parity. Although a survey such as the National Health and Nutrition Examination Survey (NHANES) has the advantage that it measures supplementation and outdoor activity, the strengths of the NDF are its large number of births/locations and the geographic identifiers for state, county, and metropolitan area which can be merged with insolation data over a long period of time. ${ }^{11}$ Existing studies on Vitamin D and infant and maternal health are typically restricted to a few cities or regions, have sample sizes of less than 200 (Narchi et al. 2010, Binkley et al. 2007), and/or fail to address the seasonal and/or regional variations that contribute to variations in Vitamin D levels (Ginde et al. 2009).

\section{III.A. Our NDF Samples}

Our baseline sample is restricted to full-term live singleton births ${ }^{12}$, stratified into births of non-Hispanic Black or White mothers. A random sample of White births is taken to eliminate large differences in sample sizes between the races. We also limit the sample to observations with birth weight between 800 and 5,000 grams (or $1 \mathrm{lb} 12 \mathrm{oz}$. and $11 \mathrm{lbs}$, respectively), mothers aged 19 to 44, and we eliminate Hawaii and Alaska. These restrictions, plus addressing coding

\footnotetext{
${ }^{10}$ Our sample begins in 1989 because that is when a revised version of the live birth certificate record was implemented, replacing the previous 1978 standard and changing the data reported. We end in 2004 because the geographic identifiers are not available in public data after that point. Also, as noted shortly, our weather data is available only through July 2006.

${ }^{11}$ While the NHANES began in the 1960s as a series of surveys, it was not a continuous survey program until 1999. It samples 5,000 persons a year "....in counties across the US, 15 of which are visited each year," (http://www.cdc.gov/nchs/nhanes/about_nhanes.htm). Moreover, NHANES III (spanning 1989-1994) surveyed northern locations in the summer and southern locations in the winter, limiting geographic/seasonal variation in the possible sun exposure experienced by respondents (Nesby-O'Dell et al. 2002).

${ }^{12}$ Full-term refers to those infants whose gestation is recorded as 37 to 42 weeks. In a robustness check discussed in detail below, we broaden our sample to include preterm births (with no restriction on weight). Unfortunately, the NDF includes no data on miscarriages or other early terminations.
} 
concerns in the Natality Detail Files with respect to maternal education ${ }^{13}$, yield sample sizes of 4,078,468 Black infants and 5,816,572 White infants. Our main dependent variable is a continuous measure of birth weight, although we estimate the baseline models using low birth weight indicators $(<2,500$ grams or $<1,500$ grams $)$ as well. As discussed shortly, in supplementary analyses we both expand the outcomes considered and use samples that include preterm births.

Limiting the sample to full-term births in our main analyses offers several advantages. Foremost, it allows us to define weather in a uniform way for all observations ${ }^{14}$, a key advantage given unique features of sunshine. Unlike other commonly studied factors (air pollution, extreme weather events, smoking, feeding programs), the expected effect of sunshine is a priori unknown and may differ during the pregnancy or across women which makes the measurement error bias caused by, for example, using a 40-week weather measure for births of all gestations very difficult to discern. ${ }^{15}$ Infant health research that studies the effects of 'extreme events' (hurricanes in Currie and Rossin-Slater 2013, death in the family in Persson and Rossin-Slater 2014) must contend with the mechanical bias that pregnancies of longer gestations are more likely to experience such extreme (and presumably detrimental) events. Such a bias seems far less likely in the case of moderate variations in weather. Our approach also reduces the need to adjust for gestation, which is likely measured with error (e.g., Howards et al. 2006). Finally and

\footnotetext{
${ }^{13}$ Missing values in the education records were cited by Baughman and Dickert-Conlin (2003) as being an issue. In our dataset, 322,706 observations were dropped from the Black sample and 317,807 from the White sample across 17 unique state/year combinations flagged in the NDF documentation.

${ }^{14}$ For all full-term observations we measure weather using the 40 weeks prior to birth. Only the month of birth is available in the public NDF data. We therefore assign all births the arbitrary birthdate of the $15^{\text {th }}$ of the month. Given the likely imprecision of the gestation measures and the possibility that sun exposure could have effects in the pre-conception period, this approach seems reasonable.

${ }^{15}$ The measurement error is systematic in that the most influential births - those preterm births with the worst outcomes - suffer from the most measurement error. The alternative approach of defining weather according to gestation (e.g., a 28 week average for a 28 week gestation) is also problematic because the effects likely differ by trimester. In addition, this alternative approach precludes including measures of weather by trimester, month, etc. Finally, the direction of bias is further compounded by the fact that weather is correlated over time, even after controlling for regular time and seasonal patterns as our model does.
} 
importantly, past work on racial disparities in infant health shows that a significant racial gap in birth weight persists when the sample is limited to full-term births, and careful studies investigate that portion of the overall gap. ${ }^{16}$ Our empirical approach and results therefore remain compatible with and relevant for existing evidence of racial disparities.

Nonetheless, focusing on full-term births has limitations. Such results must be interpreted as the effects of sunshine conditional upon reaching full term. Gestation may also be affected by weather (Beltran et al. 2014), and we explore this possibility and its implications for the full-term results in supplementary analyses that use a broader gestation sample and estimate the effects of sunshine on average gestational age, the probability of a preterm delivery or the birth of an infant who is small-for-gestational-age, as well as birth weight. However, we also note that observed outcomes from any births sample are conditional upon conception and survival, which in turn may be affected by weather. ${ }^{17}$ We therefore leave a detailed investigation for future research.

The sample sizes for the individual level data are enormous, which given the large set of models we estimate becomes computationally difficult. In addition, our key variable, insolation, only varies by county. We therefore follow the common approach (e.g., Simeonova 2011, Buckles and Hungerman 2013) of aggregating the data into county-month-year cells and weighing all analyses by the number of births in each cell. Preliminary analyses revealed very

\footnotetext{
${ }^{16}$ Lhila and Long (2012) provide a thorough discussion and literature review in their empirical study of the racial gap in birth weight. Their models and Oaxaca decomposition control for a long list of covariates including infant gender, birth order, maternal behaviors and medical risk factors, mother's and father's age, mother's education, marital status, income, place of delivery, attendant at birth, prenatal care, and an extensive set of residence characteristics such as population, unemployment rate and measures of health care (e.g. ob-gyns per capita, female mortality rate).

${ }^{17}$ Evidence from both human and animal studies suggests that sunshine and weather may affect fertility (Dror and Allen 2010, Lewis et al. 2010) as well. Data and therefore evidence on the factors affecting miscarriages is mostly non-existent. And, although the NDF includes births with gestations as short as 17 weeks, the survival rates of such births are extremely low (e.g., the probability of survival at 23 weeks gestation is only $17 \%$;

http://www.preemiesurvival.org/info/, Accessed 1/20/2015), thereby inducing serious survival bias.
} 
similar results between the aggregated data and individual level data. We create several more refined aggregates as well, further stratifying the samples by maternal age, prenatal care, smoking behavior, etc., which allows us to check whether the effects vary. Web Appendix Table A.1 lists the variables and descriptive statistics for our main samples.

\section{III.B. Insolation and Temperature Data}

We identify the latitude and longitude for each county available in the NDF, which is then matched with daily weather measurements from NASA's Atmospheric Science Data Center over the period July 1, 1983 through June 30, 2006. NASA's weather data is reported for $1^{\circ}$ latitude $\mathrm{x} 1^{\circ}$ longitude blocks ${ }^{18}$ and is therefore a 'gridded dataset' of the kind discussed in Aufhammer et al. (2013), although it is based on satellite data rather than ground-level weather stations. ${ }^{19}$ We merge NASA data with NDF data by computed conception date (based on a fixed gestation of 280 days) and county FIPS code. Figure A.1 shows the relationship between county borders and the $1^{\circ} \times 1^{\circ}$ latitude/longitude grids, and the counties available in the NDF are denoted in red. The NDF's requirement that the county population be 100,000 or greater with at least 100 births is clearly evident; many rural areas and two entire states, Idaho and Wyoming, are omitted. An important caveat to our analyses, therefore, is that they do not represent rural areas. Our key weather variables are solar insolation, which is our measure of potential sun

\footnotetext{
${ }^{18}$ One degree latitude translates to approximately 69 miles; one degree longitude is also 69 miles at the equator and shrinks gradually as one moves towards either pole. Carson $(2008,2009,2010)$ uses the same data. Counties are matched according to their geographic center; limiting the analyses to counties entirely contained within one $1^{\circ} \times 1^{\circ}$ block does not qualitatively affect our results. NASA's daily meteorological and solar energy data can be accessed at: https://eosweb.larc.nasa.gov/sse/.

${ }^{19}$ Auffhammer et al. (2013) focus on ground-level weather station datasets with .5 x .5 degree and $2.5 \times 2.5$ mile grids and measures of temperature and precipitation. The authors discuss more general issues and possible pitfalls of weather research as well. They note the difference between 'weather' and 'climate,' defining climate as 'a long average of weather at a given location' (p. 1). With our use of weather panel data and emphasis on estimating the effects of changes over time, in part to control for unobserved seasonal and geographic factors, our study is estimating the effects of weather and hence our avoidance of the word 'climate.'
} 
exposure (as in Carson 2008, 2009 and 2010), and maximum temperature. ${ }^{20}$ Insolation

represents the amount of solar energy (as measured in kilowatt-hours/meters squared/day) that reaches the surface of the Earth. Since the energy measurement captures more than just the energy derived from UV-B, it provides an upper bound of potential exposure. To assess the relationship between insolation and the duration of Vitamin D-synthesizing sun exposure, we employ Engelsen’s “VitD-ez Duration of Vitamin D Synthesis in Human Skin” calculator (Engelsen 2005) to determine the length of exposure under ideal and worst weather conditions for different dates and geographic locations. Our site-by-site comparison of the Engelsen measure with observed insolation values shows reasonably close correspondence. ${ }^{21}$

To provide context for our insolation variable, in our Web appendix we report the range of observed values for three geographically diverse cities on the shortest and longest days of the year and the spring equinox (Table A.2). The influences of season and geography are plainly evident, as it is sunnier in June than in December and in Miami and Los Angeles than in Boston. However, it also shows how much insolation varies over time, even for the same date and location, as weather conditions vary. For example, on the winter (summer) solstice, the insolation in Boston ranged from .34 to 2.45 (1.2 to 8.38) during our sample; Los Angeles and Miami display similar variation. This variation is critical to isolating the independent effect of weather in our econometric models.

To measure the effects of sun exposure during pregnancy, we calculate several averages of the daily weather variables, including for the full pregnancy (40 weeks), each trimester, and

\footnotetext{
${ }^{20}$ Minimum temperatures likely occur during the night and therefore have less of an impact. No daily data is available from NASA for wind or precipitation so we are unable to control for them in our models. Moreover, while including more weather measures has the benefit of more fully capturing weather, the high collinearity between measures and the fact that controlling for locational, seasonal and temporal factors greatly reduces their independent variation (see footnote 27) requires parsimony to identify an effect. Note that we are already more expansive than most by including two different dimensions of weather and an enormous set of location/season/time controls.

${ }^{21}$ The results of this exercise are available upon request.
} 
each month. We also calculate separate averages for weekdays versus weekends within each level of aggregation, since patterns of behavior seem likely to differ between weekdays (typical workdays and school days) and weekends (Parisi et al. 2000). The level of aggregation presents an empirical trade-off, as finer levels yield more variation in weather over time but require more coefficients to be estimated (e.g., nine coefficients for monthly aggregate values versus one coefficient for the entire 40 weeks of pregnancy). Variation in weather over time is a critical concern because we must control for unobservable geographic and seasonal effects, which we accomplish by including a variety of fixed effects.

Table 1 reports the deciles for the daily, monthly and full pregnancy (40-week) aggregates of insolation. Importantly, the distribution of insolation is the same for the Black and White samples (so we only report one set of statistics). As expected, the daily measure shows far more variation, ranging from .9 to 7.9 , whereas the month and full pregnancy measures range from 1.6 to 6.8 and 3.1 to 5.5 , respectively. We calculate the same averages for maximum temperature and include them in the models in a parallel fashion to insolation.

At the bottom of Table 1, we summarize the differences in White and Black mean birth weights for each insolation decile. This exercise reveals that the racial gap continues to shrink as one moves from the lowest deciles to the highest deciles; we further confirm that most of the differences across deciles are statistically significant. These comparisons are only descriptive, however, as they fail to control for geographic, seasonal or demographic differences, all of which are addressed in our econometric model.

\section{EMPIRICAL STRATEGY AND MODEL SPECIFICATION ISSUES}

Our empirical analyses employ a reduced form, infant health production equation that estimates the effects of the observed insolation and temperature variables on infant health as 
measured primarily by birth weight, controlling for maternal characteristics and seasonal, temporal, geographic, and selection factors. ${ }^{22}$ Unlike actual sun exposure (or Vitamin D blood levels, food diaries, etc.), observed insolation is likely exogenous to the mother (Sayers et al. 2009); this seems especially likely during our sample period when the potential benefits of Vitamin D were not heavily emphasized. ${ }^{23}$ We control for the possibility that the mother may choose where to live or when to become pregnant on the basis of typical weather with seasonand location-specific fixed effects and variables, discussed shortly, thus underscoring the importance of variation in location-month weather over time.

Coming out of a reduced form model, the estimated effects of sunshine contain the total, net effect of all its possible influences, including the possible effects weather may have on maternal behaviors and its relationship with other environmental factors such as air pollution. And as noted above, to the extent that insolation affects the ability to conceive or the length of gestation, it could affect the composition of full-term births as well, a different type of selection. While we leave a thorough analysis of these possible mechanisms for future research, we explore them in our empirical analyses to the extent permitted by our data and find little evidence that they are driving the results. Still, our results must be interpreted with these broader effects in mind. Finally, because we are estimating the effects of available sunshine, not actual sun exposure, our estimates are akin to an 'intent to treat' (ITT) effect. These nuances in interpretation are not unique to this study and are instead common to most models of

\footnotetext{
${ }^{22}$ Earlier versions of this paper contain a formal conceptual model of infant health production and utility maximization in the vein of Rosenzweig and Schultz (1982) that formally clarifies the many possible effects of sunshine. This discussion and model is available upon request.

${ }^{23}$ As noted in footnote 3, ACOG did not emphasize Vitamin D's benefits in its recommendations. To the contrary, every volume mentions its possible toxicity at high doses and states that most nutrients are adequately obtained via diet so that supplementation is not necessary. The only exception is the 1992 report which noted special circumstances in which supplementation may be desirable, including: "Vitamin D status is a special concern for women at northern latitudes in winter and for others with minimal exposure to sunlight and thus reduced synthesis of vitamin D in the skin.” (p. 181). This point is not mentioned in any other year.
} 
environmental effects, such as those investigating air pollution, temperature, or extreme weather events.

\section{IV.A. Econometric Specification}

Our main birth weight equation takes the general form of:

(1) $H_{c m t}=\beta W_{c m t}+\delta Z_{c m t}+\theta X_{c m}+\alpha_{m}+\gamma_{c t}$

where the individual NDF data have been aggregated into county-month-year cells and subscript $c$ indexes county, $m$ month, and $t$ year of birth. Every model is estimated separately for non-Hispanic Whites and non-Hispanic Blacks. $H$ denotes birth weight, $W$ includes our weather measures of insolation and maximum temperature, and $Z$ contains the county-month-year aggregates of maternal and infant characteristics. These factors include infant's gender, whether first born to mother, and mother's age, education and marital status.

The last three terms capture factors associated with geographic location, season, and the passage of time. While the typical birth weight model controls for these factors via year, state/county and, sometimes, month fixed effects, such a specification ignores the possibility that both seasonal and time trends may vary by location. For example, seasonal considerations may differ depending on location - winter in New England is different from winter in the South. Likewise, time trends may differ by location, such as the geographic variation displayed by the Medicaid expansions, which occurred during our sample period, the level of unemployment or the adoption of new medical practices such as the changed ACOG recommendations. ${ }^{24}$ Controlling for these factors is of critical importance in our model so we look to the two studies most similar to ours (Buckles and Hungerman 2013 and

\footnotetext{
${ }^{24}$ See footnote 3. Extending this logic, we acknowledge that a third possible interaction exists - seasonal patterns could vary over time due to adaptation, for example, which is emphasized in research on climate change (e.g., Deschenes 2012). However, given the relatively short period of time our sample covers (15 years), this seems the least likely to have an effect and, to our knowledge, no previous birth outcomes study has considered it.
} 
Deschenes et al. 2009) for guidance. We also explore other model specifications as robustness checks and subject each to a battery of falsification tests.

To capture location-specific seasonal selection, we follow Buckles and Hungerman (2013, henceforth BH), whose primary focus is the seasonal selection into pregnancy and its implications for the validity of season of birth as an instrument. $\mathrm{BH}$ include temperature measures expected at birth in the mother's county of residence, in addition to county fixed effects and a cubic time trend in months to control for location and time. We therefore include the average maximum temperature and insolation over the sample period for that county-month of birth, denoted as $X_{c m}$ in equation (1). To capture location-specific time trends, we follow Deschenes et al. (2009), who have a focus very close to ours - to estimate the effects of temperature on birth weight. Their models include county*year fixed effects, thus controlling for location and time as well as location-specific time effects; they also include a quartic in the day of conception $(=1$ to 365$)$ to control for seasonal influences. Following their approach, we include county*year fixed effects $\left(\gamma_{c t}\right)$, as well as month fixed effects $\left(\alpha_{m}\right)$ to capture seasonal influences. ${ }^{25}$ Note that these county*year fixed effects subsumes both county fixed effects and year fixed effects. ${ }^{26}$

The model written in equation (1) therefore captures location, seasonal and time factors, as well as location-specific seasonal selection and location-specific time effects. This model is a hybrid of BH and Deschenes et al. (2009) and, unlike those studies, it accounts for both types of location-specific factors. However, because of the lack of an

\footnotetext{
${ }^{25}$ Unlike Deschenes et al. (2009), we do not have the specific date of birth (or conception) which leads us to use month dummy variables instead.

${ }^{26}$ One could account for location-specific seasonal effects in a similar way by including county*month fixed effects. However, such a specification adds more than 5,000 fixed effects to a model which already has a very large number $(6,700+)$ fixed effects and further reduces the variation in weather. Moreover, as discussed shortly, the expected weather variables perform similarly to county*month fixed effects in our falsification tests.
} 
agreed-upon specification in existing research and the fundamental trade-off faced in choosing a specification - that the variation in weather necessarily shrinks as one more thoroughly controls for location, season, and time influences - we estimate several alternative models as robustness checks. ${ }^{27}$ We then subject each model to two falsification tests by including weather variables that should have no effect on birth outcomes. In the first test, we include the weather variables for that county/month one year in the future; in the second test, we include weather variables for that month/year from a randomly drawn county. ${ }^{28}$ We perform these tests both with and without the correct weather measures included in the model, and we conduct both individual and joint (insolation and temperature) tests. $^{29}$ As reported in Appendix Tables A.3 and A.4, these exercises suggest that our specification is appropriate. ${ }^{30}$

\section{IV.B. Modeling Weather's Effects}

Another critical specification issue is how to model the effects of weather, or the definition of $W$ in equation (1). An obvious, simple choice is to enter insolation and temperature linearly. However, it is possible that the effects of sunshine and temperature interact with one another and/or are nonlinear. For example, moderate temperatures or sun exposure may be the

\footnotetext{
${ }^{27}$ The variation in weather is strongly impacted when even the most basic controls are added. For instance, the unexplained variation in full pregnancy insolation (measured as 1-R-squared from an ancillary regression with insolation as the dependent variable) shrinks from $49.0 \%$ of the total when state and year FEs are included to 5.6\% when county, month, and year FEs are included; our primary specification retains $2.8 \%$. The temperature measures retain even less unique variation $(31.7 \%, 3.7 \%$, and $1.6 \%$, respectively) which highlights that the challenge of isolating the effects of weather extend to temperature as well - a point also made by Auffhammer et al. (2013).

${ }^{28} \mathrm{We}$ use a random number generator with replacement to assign each random county.

${ }^{29}$ A possible concern is that weather patterns could be long term or reach a wide geographic area such that our 'false' weather variables could be correlated enough with the 'correct' ones to produce a statistically significant effect. Testing the model both ways accounts for this possibility.

${ }^{30}$ Specifically, simpler models sometimes yield qualitatively different results for the weather variables and typically fail more falsification tests, especially for Blacks, while the less restrictive but much more computationally challenging model that includes the full set of county*year and county*month fixed effects (see footnote 26) performs similarly to equation (1). These findings hold for both simple linear models of weather as well as nonlinear ones, discussed next.
} 
most beneficial for health. Or, there may be a different 'dose' effect of sunshine on a mild versus cold day, as suggested by Zivin and Neidell (2010) who find that temperature has an inverted U-shaped effect on time spent in outdoor leisure activities. While no one to our knowledge has studied an interaction between sunshine and temperature on health, nonlinear effects for each one, separately, have been found. Past research on temperature emphasizes extremes and finds them detrimental (Deschenes et al. 2009; see Beltran et al. 2014 for a review). Sunshine has been much less studied, but Carson (2009) provides evidence of a quadratic effect on height. Such an effect is supported by the clinical evidence discussed in section IIB as well, as sunshine exhibits diminishing returns to the production of Vitamin D and has possibly harmful effects via folate degradation. The notion that skin pigmentation evolved as a way to balance the beneficial and harmful effects of the sun (e.g., Jablonski 2004) suggests an 'optimal' amount of sun exposure that differs by race.

We allow for more complicated relationships with two alternate models. First, we calculate averages for the full second-order polynomial of daily insolation and temperature and include them in the model. ${ }^{31}$ Second, we expand on the bins approach of Deschenes et al. (2009) who create indicator variables for different ranges of temperature (e.g., $<25^{\circ} \mathrm{F}$, $25-45^{\circ} \mathrm{F}$, etc.) We create a matrix of indicators, with three bands of insolation (dim, medium, bright) and four bands of temperature (cold, cool, warm, and hot) and calculate the number of days falling into each of the $3 \times 4=12$ categories. $^{32}$ Meaningful inference requires

\footnotetext{
${ }^{31}$ To clarify, we first compute the full polynomial of each day's weather data and then calculate the average over the pregnancy. This process is essential to retaining key variation - e.g., that 280 days of $60^{\circ} \mathrm{F}$, partly sunny weather may not have the same effect as 280 days of highly variable weather with an average of $60{ }^{\circ} \mathrm{F}$ and partial sunshine.

${ }^{32}$ Deschenes et al. (2009) include five temperature bins. Given we are measuring insolation as well, we choose slightly more parsimonious four temperature bins of $<30^{\circ} \mathrm{F}$ (cold), $30-50{ }^{\circ} \mathrm{F}(\mathrm{cool}), 50-80{ }^{\circ} \mathrm{F}$ (warm), and over 80 ${ }^{\circ} \mathrm{F}$ (hot). For insolation, we divide it into three equal ranges of $<3,3$ to 6 , and over $6 \mathrm{kw} \cdot \mathrm{h} / \mathrm{m}^{2} /$ day. The coldest temperature-lowest insolation bin is the reference category. We also investigate an even finer breakdown of sunshine, dividing it into six equal ranges ( 0 to $1.5,1.5-3$, etc.) and yielding 24 categories $(=6 \times 4)$, and find similar results.
} 
making comparisons across cells - e.g., whether moving from a cold, partly sunny day to a cold sunny day has a positive effect. We therefore conduct a complete set of tests of such comparisons; these tests and results are reported in Appendix Table A.5 and Figure A.2. Both alternative models yield similar conclusions. For White mothers, the simple linear model of weather finds strong support. None of the nonlinear terms in the polynomial model are ever statistically significant, and in the bins model, a monotonic relationship is confirmed. Conversely, both models suggest strong nonlinearities for Black mothers, especially for sunshine. The nonlinearity of temperature's effect is less clear and there is little evidence of an interaction between sunshine and temperature. ${ }^{33}$

We therefore emphasize results from a model that includes the quadratic of insolation and temperature for Blacks and, for ease of exposition, the linear model for Whites. However, we verify that the results are qualitatively unchanged if we instead use the quadratic model for Whites as well. ${ }^{34}$ We also verify that equation (1) is still the appropriate model when quadratic effects are included (reported in Web Appendix Tables A.6 and A.7).

\section{RESULTS}

Our main results, shown in Figure 1 and Table 2, suggest that sunshine has different effects on the birth weight for Blacks versus Whites. For Black mothers, sunshine has a positive, diminishing effect on birth weight that becomes negative when average insolation reaches 5.5, a

\footnotetext{
${ }^{33}$ Deschenes (2012, Table 1) reports a similar insignificant finding in a study that allows for an interaction between humidity and temperature, the only one to our knowledge that allows for an interaction between weather measures. ${ }^{34}$ Our quadratic results for Whites are qualitatively the same as the linear results but much more tedious to interpret. The signs of the linear and squared terms frequently change across specifications but the calculated turning points all indicate a negative effect of insolation throughout - i.e., the turning point occurs outside the range of sample values -- or both effects are negative. In addition, the majority of individual coefficients are not statistically significant, likely obscured by over-parameterizing its effects, while their joint significance typically mirrors the results of the linear model.
} 
very high level of sun exposure in our data (occurring at the 90th percentile; see Table 1). In contrast, sunshine has a negative effect on birth weight for White mothers. While our main model requires the effect to be linear for Whites, the results from a quadratic model yield a strikingly similar conclusion, as shown in Appendix Figure A.3.

These results are entirely plausible given the clinical evidence presented in section IIb. White mothers are less likely to be deficient in Vitamin D and their lesser skin pigmentation leaves them more vulnerable to the harmful effects of sunshine, so that a net, negative marginal effect of sun exposure makes sense. Conversely, Black mothers suffer much more widespread Vitamin D deficiency and their greater skin pigmentation both requires more sun exposure to produce it and protects them from harmful effects. Even so, it makes sense that there are diminishing returns to sun exposure, both in terms of producing Vitamin D and in the net benefits to health of increased Vitamin D versus reduced folate. In terms of evolutionary hypotheses (e.g., Jablonski 2004, Borradale 2013), these results are consistent with White mothers living in locations at or above their health-optimizing level of sun exposure and Black mothers living below it. It further suggests that sun exposure could play a role in explaining the racial gap observed in U.S. birth outcomes - an issue we revisit in detail below.

Next, we explore if the timing of weather matters, either during the pregnancy or on weekends versus weekdays. A key advantage of our analyses is that we observe the mothers' daily potential exposure to insolation throughout the pregnancy, whereas most past studies have only observed Vitamin D, folate or sun exposure at one point during the pregnancy. Given the well-established importance of the first trimester to infant health (Smith et al. 1998) and the fact that fetal weight gain is the largest in the third trimester (Olsen et al. 2010), one might expect stronger effects in these trimesters. Existing evidence for sunshine and Vitamin D is very limited 
and mixed (Beltran et al. 2014). ${ }^{35}$ The evidence for folate, which recall may be reduced by sun exposure, suggests a positive relationship between folate measured at delivery (or in the third trimester) and birth weight, but evidence for early trimesters is scarce (Scholl and Johnson 2000). Differential effects of sunshine across the pregnancy therefore appear both plausible and empirically unresolved.

We re-estimate our main model using weather aggregated by trimester and then by month (Table 2) and plot the estimated effects by trimester (Figures 2 and A.4). These exercises suggest that sunshine has a fairly similar effect on birth weight throughout the pregnancy. While some trimesters yield more statistically significant coefficients (i.e., $1^{\text {st }}$ and $3^{\text {rd }}$ for Blacks, $1^{\text {st }}$ and $2^{\text {nd }}$ for Whites), the estimated magnitudes are similar and are not statistically different from one another. They also are remarkably consistent with what we find for the full pregnancy. For Black mothers, insolation has a positive but diminishing effect becoming negative once average insolation exceeds 5. For White mothers, a one unit change in insolation reduces birth weight by 6-7 grams and these reductions are fairly evenly distributed across the trimester (1.5 to 2.8 each). These findings are further supported by looking at the effects by month. While understandably yielding fewer statistically significant coefficients, the coefficients are jointly significant at the $1 \%$ level and the same patterns arise. The estimated effects are consistently negative for White mothers and of the greatest magnitude in the first five months. For Black mothers, the same quadratic pattern appears throughout the pregnancy with the largest magnitudes in the first and last months.

Allowing the effects of weather to differ on weekends vs. weekdays yields results consistent with past research that suggests people spend more time outdoors on weekends than

\footnotetext{
${ }^{35}$ Moreover, this evidence comes from primarily descriptive analyses. Brannon and Picciano (2011) discuss how Vitamin D production accelerates and takes place during the different trimesters of pregnancy but no consensus about differential effects of supplementation appears to exist.
} 
on weekdays (Parisi et al. 2000). ${ }^{36}$ While none of the weekend effects are statistically significant, the point estimates are consistent with greater exposure (Table 3). Moreover, the pattern of effect is again remarkably consistent across trimesters. For Whites that means an even more negative effect of sunshine (roughly double) on weekends. For Blacks, the level of sunshine at which diminishing returns sets in is lower and the marginal effects at the extremes are greater - i.e., the parabola is more sharply curved and reaches a maximum at a lower level of insolation - on weekends.

All of the above analyses investigate the effects of weather on continuous birth weight, whereas a low birth weight indicator is arguably more clinically meaningful. We therefore reestimate all of the models in Tables 2 and 3 using the percentage of births that are low birth weight $(<2,500$ grams $)$ or very low birth weight $(<1,500$ grams $)$. The estimated effects of insolation are quite consistent with those using the continuous measure, although their statistical significance is sometimes diminished, especially in the full pregnancy model. We therefore conclude that insolation has similar effects on the incidence of low birth weight as on continuous birth weight.

\section{V.A The Possible Role of Air Pollution and Maternal Behaviors}

Our next set of analyses explores whether our results could work through other mechanisms such as air pollution or maternal behaviors and characteristics. As noted above, air pollution's effect on birth outcomes has been widely studied and evidence suggests that air pollution is correlated with weather. Daily air pollution data does not exist for all of the counties and time periods in our sample, so we tackle this issue with two complementary exercises

\footnotetext{
${ }^{36} \mathrm{We}$ include an additional variable, the average insolation on weekend days (only) during the pregnancy, *Weekend, which is essentially an interaction term. We do not report these results for the monthly model as the large number of weather coefficients eliminates all statistically significant effects.
} 
(reported in Table 4). First, we create two subsamples - the 'cleanest' versus 'dirtiest' counties in our sample during our sample time period. ${ }^{37}$ For both races, the point estimates suggest stronger effects in 'clean' counties than in 'dirty' ones - or in the overall sample. Our second exercise controls for the time-varying aspect of air pollution. For the 106 (out of 458) counties for which daily air quality index (AQI) data is available for our entire sample period, we create air pollution measures in the same way as the weather measures and add them to the model. Although only about $25 \%$ of the main sample, this subset of counties yields results similar to our main model (Table 4, first two rows of Panel B). Moreover, adding the AQI measure has no appreciable impact on the estimated effects of insolation and temperature and, while negative as expected, is itself not statistically significant (third row of Panel B). On the other hand, excluding insolation, temperature and expected weather from the model yields a negative and statistically significant effect for Whites (last row). These two exercises therefore suggest that the weather effects we find are not being driven by air pollution.

It is also possible that the effects of insolation operate through maternal characteristics and behaviors, which we explore by stratifying the sample (Table 5). ${ }^{38}$ Maternal age may capture both baseline health and behaviors, and our results suggest that sunshine has more negative (or less positive) effects for younger mothers. This finding is consistent with the notion that younger mothers spend more time out in the sun (i.e., receive a higher dose), similar to the

\footnotetext{
${ }^{37}$ We use daily values of the Air Quality Index (AQI) Report generated by the United States Environmental Protection Agency, updated in 2013, to construct county-level measures of pollution. The AQI ranges from 0 to 500 with higher values indicating more air pollution. It has much greater availability during the sample time period than any other measure. For instance, the PM2.5 measure is rarely, if ever, available before 1999. Nonetheless, most counties are missing a substantial number of days -- and often entire months -- of data. For the 'clean' vs. 'dirty' exercise, we first calculate the percentage of low pollution, 'clean' days $(\mathrm{AQI}<50)$ and high pollution, 'dirty' days (AQI > 100 - the range of 101-150 is considered unhealthy for sensitive groups) in each county. We then define clean counties as those in the top quintile of counties with the least pollution (highest percentage of 'clean' days) and dirty counties as those with the highest pollution (highest percentage of 'dirty' days).

${ }^{38}$ Prenatal care, smoking and even age and air pollution may all be endogenous and therefore stratifying the sample on this basis could cause bias. We therefore view these results as a merely illustrative exploration into whether other avenues for effect may be at work.
} 
'weekend effect,' and/or have higher baseline levels of Vitamin D. ${ }^{39}$ Stratifying by prenatal care status points to a similar pattern. Women with adequate prenatal care (who are likely informed on diet and vitamin supplementation; e.g., Kogan et al. 1994) experience more negative/less positive effects of insolation. ${ }^{40}$ The possibility that nice weather could lead to harmful health behaviors (e.g., going outside to smoke) is not supported by the limited exercise we perform with our data - stratifying by smoking behavior. Instead, the positive effects of insolation for Blacks are slightly smaller and the negative effects for Whites are slightly stronger for nonsmoking mothers; still, the general findings are similar to the overall sample.

\section{V.B. Exploring Compositional Effects and Additional Birth Outcomes}

So far, we have limited our investigation to the birth weight of full-term infants so that we can focus on fetal growth (as opposed to gestation) and precisely model the effects of weather during pregnancy. However, this approach obscures other possible mechanisms for sunshine to have an effect. While an in depth analysis of multiple pregnancy outcomes is beyond the scope of this paper ${ }^{41}$, in this section we explore the extent to which alternative mechanisms may exist and are affecting our results.

Past research suggests that insolation could affect gestation length and even the ability to

\footnotetext{
${ }^{39}$ Existing research is of limited guidance because results are not typically reported by these age groups. Godar et al. (2001) report time spent outside for women 22-40 and 41-59 and find no consistent pattern between the two age groups; our three groups fall primarily within their younger category. Looker et al. (2011) report the distribution of Vitamin D levels for women aged 19-30 and 31-50, a little closer to our age groups. They find higher levels of Vitamin D for the younger group at every Vitamin D decile except for the lowest one.

${ }^{40}$ The general similarity between those with and without adequate prenatal care is also suggestive that the changed ACOG guidelines during the time period are not unduly affecting our results.

${ }^{41}$ For instance, the effects of sunshine and temperature on fertility must take into account male reproductive health and the effects on sexual activity and have thus been studied in a mostly separate empirical literature. While the survey papers cited in section II report some evidence for these outcomes, very few, if any, individual studies investigate both birth outcomes and fertility. More generally, problems in accurately modeling the effects of weather on outcomes that occur throughout the reproductive process are highlighted by the richness of our data; observing weather on a daily basis, we find evidence that it matters throughout the pregnancy. This insight suggests developing a new, survival analysis-type framework in which the intervention or exposure is continually updated as the pregnancy is conceived and then survives each week, month, or trimester. We are unaware of any past study that has attempted it.
} 
conceive (e.g., see Dror and Allen 2010 for a review). Because our main sample is limited to full-term births, our reduced form estimates may be capturing those compositional effects as well. For example, if insolation improves the likelihood of conceiving and/or surviving to an observable gestation, it could change the 'quality' of the marginal pregnancy - and therefore its gestation and the overall composition of full-term births. We investigate this possibility in several ways. First, we re-estimate our model excluding all maternal and infant characteristics. These estimates can be interpreted as the broadest possible reduced form effects by also capturing the impact that insolation may have on the characteristics of mothers giving birth to full-term infants. It is therefore reassuring to find that they are very similar to those of our main model (first two rows of Table 6). ${ }^{42}$ Second, we include the average insolation and maximum temperature in the two months prior to the conception month to capture any possible effects of weather on conception and thus selection into our sample. The results are once again qualitatively the same (bottom row of Table 6), and the preconception weather coefficients are nowhere close to statistical significance.

Finally, we explore more birth outcomes by expanding our sample to include preterm births ( $\geq 28$ weeks $)^{43}$ and by considering gestation and fetal growth separately, as well as a proxy for survival, percent male (Drevenstedt et al. 2008). However, expanding the sample in this way means that the timing and extent of insolation actually experienced depends on gestation. And,

\footnotetext{
${ }^{42}$ By the same reasoning, one might argue that these characteristics should be dropped from all of the analyses. However, such an approach deviates markedly from past research; for instance, Currie et al (2009), Deschenes et al (2009), and Currie and Rossin-Slater (2013) all include infant and maternal characteristics. Alternatively, one could see if these characteristics are themselves affected by insolation. In analyses available upon request, we find some evidence of positive selection for Blacks, but none for Whites. Nonetheless, all of our birth weight analyses are robust to their exclusion, which suggests that any selection is not having a substantial effect on our results. Moreover, to the extent that positive selection does exist, including these characteristics leads to more conservative estimates of insolation's effect.

${ }^{43}$ Unlike in our full-term birth sample, in these analyses we place no restrictions on the range of birth weights. While the NDF reports births with gestations as low as 17 weeks, including these births is problematic for several reasons: Earlier gestations are less likely to be viable (such that our selection on live births could be more problematic), are fairly rare yet could be influential given their extreme values, and may not have experienced even the full second trimester of weather.
} 
given we find evidence that insolation continues to be important in even the last trimester of pregnancy, including only first trimester weather measures, for example, could cause omitted variable bias. To address this problem and also remain comparable with our main analyses and our intent-to-treat framework, we include the weather measures for all three trimesters. We expect the estimated effects of insolation to be attenuated to the extent that infants of lesser gestations are not exposed fully to the third trimester; note that these infants also typically experience the worst outcomes so the measurement error is systematic with the dependent variable. Because we find variations in weather to be correlated across trimesters (even after controlling for location, season and time), this bias may spread to the other trimesters. Indeed, this is one of the key reasons why we choose to consider full-term births in our main analyses.

For Black infants' mean birth weight, first trimester insolation continues to have the strongest effect and may be even more beneficial in this expanded sample (top left hand corner of Table 7 as compared with Table 2). Insolation in the second trimester shows little significant effect as before while the estimated effects of third-trimester insolation are diminished, as expected, by including earlier gestations. ${ }^{44}$ For White mothers, it is now only second trimester insolation that significantly (and negatively) affects mean birth weight. While we would expect a diminished effect in the third trimester due to the systematic measurement error, the diminished effect in the first trimester turns out to be revealing of insolation's impacts on gestation - a mechanism that explains the stronger first trimester effects for Blacks as well.

\footnotetext{
${ }^{44}$ These findings are confirmed by and are even stronger in linear models. Insolation is positive in all three trimesters and is strongly statistically significant in the first and marginally so in the third trimesters.
} 
Birth weight is a product of both gestational age and fetal growth. By conditioning on full-term births in our main analyses, we are focusing on fetal growth. ${ }^{45}$ In our expanded sample, however, birth weight captures much more of the effects of gestation as the most extreme low birth weights are nearly always preterm births. When including births with a wide range of gestations, we therefore decompose the two effects by separately investigating gestational outcomes (the percentage of preterm births and the mean gestational age), and fetal growth conditioned on gestation (measured by the 'small-for-gestational-age', SGA, indicator ${ }^{46}$ ). Our results suggest that first trimester insolation increases gestational age for both Blacks and Whites. These beneficial impacts on gestation therefore explain why the effects of first trimester insolation on birth weight become more positive when broader gestations are included. Second trimester insolation appears to behave in the opposite way, albeit with less significant effects; if anything, it shortens gestation for both races and thus may similarly help explain why the effects become more negative. Third trimester insolation acts similarly to the first, although as expected its estimated effects are attenuated.

Our analyses in Table 7 therefore suggest that insolation affects gestation of Blacks and Whites in a similar way, but that the effects vary in sign by trimester. These results help explain the differences we see for mean birth weight between the full-term sample and the one that includes preterm births. In addition and importantly for our main research question, these analyses suggest that the ability of insolation to explain the racial gap in fetal growth (conditional upon gestation) remains. In particular, insolation consistently increases the SGA

\footnotetext{
${ }^{45}$ This interpretation is supported by models estimated with our full-term sample using mean gestational age as the outcome. The insolation coefficients are never individually or jointly statistically significant, suggesting that insolation has no effect on late pregnancy gestation.

${ }^{46} \mathrm{We}$ construct a binary measure of SGA using the gestation specific birth weight percentiles calculated in Oken et al. (2003) who evaluate births from the 1999-2000 Vital Statistics. For each birth, SGA is coded as 1 if the infant's birth weight falls below the $10^{\text {th }}$ percentile for the relevant gestation length, or 0 otherwise. While this practice is standard, the resulting measure is noisy both because of measurement error in gestation and because of the arbitrary cut-off at the $10^{\text {th }}$ percentile.
} 
more (or decreases it less) for Whites than Blacks. Moreover, our mean birth weight estimates imply that uniform increases in sunshine exposure would have a comparable impact on closing the observed racial birth weight gap in both samples. ${ }^{47}$ We discuss the magnitude of this impact in the next section. Still, the possibly beneficial effects of sunshine exposure on gestation for Whites suggest caution in using our findings to conclude that insolation is purely harmful for White mothers.

Our last set of exercises explores whether survival (as measured by percent male) is affected by insolation and, more generally, whether conception and survival selection mechanisms could be at play. Little evidence exists that percent male is affected by insolation for either race (bottom of Table 7). ${ }^{48}$ However, unlike in our main analyses using full-term births, we find the preconception weather variables have statistically significant, beneficial effects on mean birth weight and gestational age (but not SGA). ${ }^{49}$ These findings further suggest that insolation affects gestation differentially from fetal growth and imply that future work, perhaps taking into account weather prior to conception, is warranted.

\section{V.C. Putting the Magnitudes in Context and their Implications for Racial Disparities}

Taken together, these analyses suggest that insolation affects the birth weight - and specifically the fetal growth - of infants differently by race and in such a way that it may explain a nontrivial portion of the observed racial gap in birth weights. Our results consistently point to a positive but diminishing effect of insolation on birth weight for Black mothers and a steady, negative effect for White mothers. These findings are consistent with the presumed positive but

\footnotetext{
${ }^{47}$ Calculations available on request.

${ }^{48}$ Similar to our findings for mean gestation age, the effects on percent male are even weaker in our full-term sample.

${ }^{49}$ Including preconception weather does not substantively affect the results, however. Likewise, the results are robust to excluding maternal characteristics. These exercises are available on request.
} 
diminishing effects of sunshine via Vitamin D - the production of which is inhibited by skin pigmentation and is more likely found to be deficient for Black mothers - balanced against possible negative effects of sunshine via folic acid depletion and immune system impairment.

Recall that our measure of insolation captures potential sun exposure during pregnancy. Its effect on birth weight therefore varies by how it translates into actual exposure as well as by the baseline Vitamin D status of the mother. Here again, the pattern of the estimated effects tells a consistent story, suggesting stronger effects when the actual exposure is likely greatest (weekends) and a more negative effect when Vitamin D may be more likely sufficient (younger mothers). The fact that we are capturing potential exposure also suggests that our estimated effects are a lower bound on the effects of actual exposure. ${ }^{50}$

The estimated magnitudes of insolation's effect on birth weight are fairly small and comparable with those found for other determinants of birth weight. In our baseline full-term specification, a one unit increase (approximately 1.5 standard deviations) in full-pregnancy insolation is estimated to decrease birth weight by 6.5 grams for White mothers. The quadratic model estimated for Blacks complicates the interpretation of magnitudes (recall Figure 1). For a Black mother experiencing the mean insolation (4.16), which is nearing the point where insolation's effect is no longer positive, a one-unit increase in insolation increases birth weight by only 3.2 grams. However, a decrease of one unit decreases birth weight by more than double that amount, 6.7 grams. Another comparison uses the deciles of insolation and birth weights

\footnotetext{
${ }^{50}$ For instance, Siikamaki (2009) finds that individuals (men + women) aged 18-35 spent about 3.2 hours per week on outdoor recreation in 1993; in addition, women spent about 58\% as much time as men. Combining these two numbers suggests that women aged 18- 35 spent about 2.3 hours per week on outside recreation. This translates to less than $3 \%$ of the average daylight hours - potential sun exposure - in a typical week (12 hours $x 7$ ). However, the difference between potential and actual exposure could differ systematically by race or even insolation and so deriving the effect of actual exposure is likely more complicated. In addition, recall that solar insolation captures more than just UV-B, the catalyst for producing Vitamin D. Finally, due to the large number of geographic and seasonal variables we include, our estimates are only picking up the effects of weather, not the more persistent and perhaps more substantial effects of climate (long term weather).
} 
reported in Table 1. Here, our baseline full-term model suggests that increasing insolation from the lowest to the highest decile (3.1 to 5.5) increases birth weight of Black mothers by 10.7 grams. For White mothers, the decrease is 15.7 grams, an effect that is roughly the same size as the estimated beneficial effect of actually participating in the food stamp program (Almond et al. 2011) and only slightly less than that of the WIC program (Hoynes et al. 2011). ${ }^{51}$

The magnitudes of our estimated effects are in the same range as those found for season, temperature, extreme weather events, and air pollution. BH (Table 1 on p. 714) report seasonal effects on birth weight that range from -.87 grams (December birth) to 23.34 grams (April birth) relative to a January birth. Deschenes et al. (2009, p. 214) find a decrease in birth weight of .003 to .009 percent ( .1 to .3 grams) per hot day (over $85^{\circ} \mathrm{F}$ ). Simeonova (2011) finds small effects of natural disasters, less than 5 grams, and makes the point that her measure - like ours - is only capturing potential exposure and thus the effects of actual exposure could be much higher. In their study of air pollution, Currie et al. (2009, p. 696) acknowledge the generally modest birth weight effects typically found, comparing their own results (e.g., a 1 unit increase in $\mathrm{CO}$ - which is more than one standard deviation - in the third trimester reduces mean birth weight by 16.65 grams) to similarly modest effects for maternal smoking, which is widely acknowledged to have important effects on infant health.

Moreover, because we find strong racial differences in the effects of insolation, it is possible that they can help explain the racial gap in birth outcomes. In our full-term sample, the gap in mean birth weight between White and Black mothers is 214 grams. As just reported, our estimates suggest that moving from the $1^{\text {st }}$ to the $10^{\text {th }}$ decile in insolation closes the gap by about 26 grams (15.7 g decrease for Whites $+10.7 \mathrm{~g}$ increase for Blacks), so around $12 \%$ from the

\footnotetext{
${ }^{51}$ These are 'treatment on the treated' effects; Almond et al. (2011, p. 388) report an increase in mean birth weight of $.5 \%$, or approximately 17 grams, while Hoynes et al. (2011, p. 824) report an effect of 18 to 29 grams. Both studies find larger effects on low birth weight.
} 
baseline. ${ }^{52}$ This finding also echoes the pattern in our descriptive analyses when we compare mean birth weights by insolation decile and find a 43 gram difference between the highest and lowest deciles (Table 1). For comparison, the racial gap in mean birth weight shrinks by 40 grams when we limit the sample to college-educated mothers. Our analyses therefore suggest that sun exposure and its effects on birth weight may explain a nontrivial portion of the racial gap in birth outcomes.

\section{CONCLUDING REMARKS}

Sun exposure has possible direct effects on birth outcomes - and health status more generally - that are biologically plausible and may differ by race; as such, it has the potential to help explain persistent racial disparities. Moreover, sun exposure is associated with many other factors that have received a great deal of attention in the health economics literature - extreme temperatures and weather events, air pollution, and season of birth. Understanding its direct effects on birth outcomes therefore has strong implications for past research as well as for ways to improve birth outcomes (e.g., through increased Vitamin D or folic acid supplementation).

Empirical identification of these direct effects, however, is challenged by the strong influences that geography, season, and the passage of time have on birth outcomes and the likelihood that sunshine may have indirect effects via maternal behaviors and environmental factors such as air pollution. We tackle these challenges by estimating a carefully specified empirical model using detailed data on both birth outcomes and daily weather that span many geographic areas across the US and a long period of time (1989-2004). We subject our model to a battery of falsification tests and robustness checks, and also estimate a range of alternative

\footnotetext{
52 This calculation is merely illustrative as it does not incorporate the current, different locations of Blacks versus Whites or the role of climate (regular weather), both of which are reflected in the baseline racial gap observed in our data.
} 
models that allow sunshine and temperature to have more complicated effects on birth weight. These analyses consistently suggest that sun exposure is beneficial for the fetal growth of Blacks and may be harmful for Whites. This finding is wholly consistent with the established tendency of Black mothers to suffer from greater Vitamin D deficiency and the role that skin pigmentation has in the effects of sun exposure. Our estimated effects of sunshine on the birth weight of full-term infants, while modest in size, are in line with other determinants of birth weight such as feeding programs, extreme weather events and air pollution. Moreover, because the effects of sunshine are estimated to diverge by race, these estimated effects represent a nontrivial portion of the racial gap observed in birth weight. Exploring the policy implications of these results - e.g., increased Vitamin D supplementation for Black mothers and avoidance of the sun for White mothers - as well as the effects that sun exposure may have on other aspects of the birth process (fertility, gestation, other measures of infant health), and on health outcomes more generally are worthwhile directions for future research. 


\section{References}

Aizer, Anna, Laura Stroud and Stephen Buka. 2012. "Maternal Stress and Child Outcomes: Evidence from Siblings," NBER Working Paper 18422.

Almond, Douglas, Hilary Hoynes, and Diane Whitmore Schanzenbach. 2011. "Inside the War on Poverty: The Impact of Food Stamps on Birth outcomes," Review of Economics and Statistics, 93(2): 387-403.

American Academy of Pediatrics and the American College of Obstetricians and Gynecologists. 1983. Guidelines for Perinatal Care. (1 ${ }^{\text {st }}$ ed.). Elk Grove Village, IL: 166-177.

AAP/ACOG. 1988. Guidelines for Perinatal Care. (2nd ed.). Elk Grove Village, IL: 193-196.

AAP/ACOG. 1992. Guidelines for Perinatal Care. (3rd ed.). Elk Grove Village, IL: 177-181.

AAP/ACOG. 1997. Guidelines for Perinatal Care. (4th ed.). Elk Grove Village, IL: 281-283.

AAP/ACOG. 2002. Guidelines for Perinatal Care. (5th ed.). Elk Grove Village, IL: 79-83.

Andalón, Mabel, João Pedro Azevedo, Carlos Rodríguez-Castelán, Viviane Sanfelice, and Daniel Valderrama. 2014. "Weather Shocks and Health at Birth in Colombia," World Bank Group Policy Research Working Paper 7081.

Arab, Lenore, Alicia Carriquiry, Susan Steck-Scott and Mia M. Gaudet. 2003. "Ethnic differences in the nutrient intake adequacy of premenopausal US women: results from the third national health examination survey," Journal of the American Dietetic Association. 103(8): 1008-14. doi:10.1016/S0002-8223(03)00474-7.

Auffhammer, Maximilian, Solomon M. Hsiang, Wolfram Schlenker, and Adam Sobel. 2013. "Using Weather Data and Climate Model Output in Economic Analyses of Climate Change,” NBER Working Paper No. 19087.

Basu, Rupa, Brian Malig, and Bart Ostro. 2010. "High Ambient Temperature and the Risk of Preterm Delivery," American Journal of Epidemiology, 172(10): 1108-17.

Baughman, Reagan and Stacy Dickert-Conlin. 2003. "Did Expanding the EITC Promote Motherhood," American Economic Review. 93(2): 247-251. doi:10.1257/000282803321947137

Beltran, Alyssa J., Jun Wu, and Olivier Laurent. 2014. "Associations of Meteorology with Adverse Pregnancy Outcomes: A Systematic Review of Preeclampsia, Preterm Birth and Birth Weight," International Journal of Environmental Research and Public Health. 11: 91-172. 
Binkley, N. and R. Novotny, D. Krueger, T. Kawahara, Y.G. Daida, G. Lensmeyer, B.W. Hollis, M.K. Drezner. 2007. "Low vitamin D status despite abundant sun exposure," Journal of Clinical Endocrinology and Metabolism. 92(6): 2130-2135. doi: 10.1210/jc.2006-2250

Basso, Olga; Olsen, Jørn; Bisanti, Luigi; Juul, Svend; Boldsen, Jesper. 1995. "Are Seasonal Preferences in Pregnancy Planning a Source of Bias in Studies of Seasonal Variation in Reproductive Outcomes?," Epidemiology. 6(5): 520-524.

Bodnar, Lisa M., Janet M. Catov, Joseph M. Zmuda, Margaret E. Cooper, Meredith S. Parrott, James M. Roberts, Mary L. Marazita, and Hyagriv N. Simhan. 2010. "Maternal serum 25-hydroxyvitamin D concentrations are associated with small-for-gestational age births in white women," Journal of Nutrition. 140(5): 999-1006. doi: 10.3945/jn.109.119636

Bodnar, Lisa M., and Hyagriv N. Simhan. 2010. "Vitamin D may be a link to black-white disparities in adverse birth outcomes," Obstetrical Gynecological Survey, 65(4): 273-284. Retrieved from http://www.ncbi.nlm.nih.gov/pubmed/20403218

Bodnar, Lisa M., Hyagriv N .Simhan, Robert W. Powers, Michael P. Frank, Emily Cooperstein, and James M. Roberts. 2007. "High prevalence of vitamin D insufficiency in black and white pregnant women residing in the northern United States and their neonates," Journal of Nutrition.137(2): 447-452.

Borradale, David. 2013. "Investigating the association between sun exposure and folate degradation in the human body," PhD Thesis, Queensland University of Technology.

Brannon, Patsy M. and Mary Frances Picciano. 2011. "Vitamin D in Pregnancy and Lactation in Humans," Annual Review of Nutrition, 31: 89-115.

Brien, Michael J. and Christopher A Swann. 2001. "Prenatal WIC Participation and Infant Health: Selection and Maternal Fixed Effects," Manuscript, UNC Greensboro Department of Economics.

Buckles, Kasey S. and Daniel Hungerman. 2013. "Season of Birth and Later Outcomes: Old Questions, New Answers," Review of Economics and Statistics, 95(3): 711-724.

Byers, Katherine G. and Dennis Savaiano. 2005. "The Myth of Increased Lactose Intolerance in African-Americans," Journal of the American College of Nutrition. Vol. 24, No. 90006, 569S-573S.

Carson, Scott Alan. 2008. "The Effect of Geography and Vitamin D on African-American Stature in the $19^{\text {th }}$ Century: Evidence from Prison Records," Journal of Economic History, 68(3): 812-830.

Carson, Scott Alan. 2009. "Geography, Insolation and Vitamin D in 19th Century US AfricanAmerican and White Statures," Explorations in Economic History. 46(1): 149-159. 
Carson, Scott Alan. 2010. "Nineteenth Century Mexican Statures in the United States and their Relationship with Insolation and Vitamin D," Journal of Biosocial Science. 42: 113-128.

Cassidy-Bushrow Andrea E.; Rosalind M. Peters, Dayna A. Johnson, Jia Li, and D. Sudhaker Rao. 2012 "Vitamin D Nutritional Status and Antenatal Depressive Symptoms in African American Women," Journal of Women's Health. 21(11): 1189-1195. doi:10.1089/jwh.2012.3528.

CDC. 2008. "National Report on Biochemical Indicators of Diet and Nutrition in the U.S. Population 1999-2002: Fat-Soluble Vitamins \& Micronutrients: Vitamin D" (http://www.cdc.gov/nutritionreport/99-02/part_2b.html; Accessed 07/26/2012).

Cullen, Mark R., Clint Cummins, and Victor R. Fuchs. 2012. "Geographic and Racial Variation in Premature Mortality in the US: Analyzing the Disparities," NBER Working Paper \#17901.

Currie, Janet, Matthew Neidell and Johannes F. Schmeider. 2009. "Air Pollution and Infant Health: Lessons from New Jersey,” Journal of Health Economics. 28(3): 688-703.

Currie, Janet. 2011. "Inequality at Birth: Some Causes and Consequences," American Economic Review: Papers \& Proceedings, 101(3): 1-22.

Currie, Janet and Maya Rossin-Slater. 2013. "Weathering the Storm: Hurricanes and Health Outcomes," Journal of Health Economics. 32(3): 487-503.

Daly, Leslie E., Peadar N. Kirke, Anne Molloy, Donald G. Weir, and John M. Scott. 1995. "Folate Levels and Neural Tube Defects: Implications for Prevention," Journal of the American Medical Association. 274(21): 1698-1702.

Deschenes, Olivier. 2012. "Temperature, Human Health, and Adaptation: A Review of the Empirical Literature,” NBER Working Paper \#18345.

Deschenes, Olivier, Michael Greenstone and Jonathan Guryan. 2009. "Climate Change and Birth Weight,” American Economic Review: Papers \& Proceedings, May, 99(2): 211-7.

Deschenes, Olivier and Enrico Moretti. 2009. "Extreme Weather Events, Mortality and Migration," Review of Economics and Statistics, 91(4): 659-81.

Drevenstedt, Greg L., Eileen M. Crimmins, Sarinnapha Vasunilashorn, and Caleb E. Finch. 2008. "The rise and fall of excess male infant mortality," PNAS, 105(13): 5016-21.

Dror, Daphna K. and Lindsay H. Allen. 2010. "Vitamin D Inadequacy in Pregnancy: Biology, Outcomes and Interventions," Nutrition Reviews. 68(8): 465-77.

Dubay, Lisa; Ted Joyce, Robert Kaestner, and Genevieve M. Kenney. 2001. "Changes in Prenatal Care Timing and Low Birth Weight by Race and Socioeconomic Status: 
Implications for the Medicaid Expansions for Pregnant Women," HSR: Health Services Research. 36(2).

Engelsen, Ola. 2005. "VitD-ez Duration of Vitamin D Synthesis in Human Skin." (http://zardoz.nilu.no/ olaeng/fastrt/VitD-ez.html).

Food and Drug Administration (FDA), Department of Health and Human Services. 2011. "Code of Federal Regulations: Food for Human Consumption," (Vitamin $\mathrm{D}_{3}$ at: http://www.accessdata.fda.gov/scripts/cdrh/cfdocs/cfCFR/CFRSearch.cfm?fr=172.380 and Vitamin $\mathrm{D}_{2}$ at: http://www.accessdata.fda.gov/scripts/cdrh/cfdocs/cfCFR/CFRSearch.cfm?fr=172.379; Accessed 07/26/2012).

Fukuwatari, Tsutomu, Mio Fujita, and Katsumi Shibata. 2009. "Effects of UVA Irradiation on the Concentration of Folate in Human Blood," Bioscience, Biotechnology, and Biochemistry, 73(2): 322-327.

Fuller, Kathleen E. 2000. "Low Birth-Weight Infants: The Continuing Ethnic Disparity and the Interaction of Biology and Environment," Ethnicity and Disease. 10: 432-445.

Gale, CF, SM Robinson, NC Harvey, MK Javaid, B Jiang, CN Martyn, KM Godfrey, C Cooper and The Princess Anne Hospital Study Group. 2008. "Maternal vitamin D status during pregnancy and child outcomes," European Journal of Clinical Nutrition. 62(1): 68-77.

Ganji, Vijay; Cristiana Milone, Mildred M. Cody, Frances McCarty, and Yong T Wang. 2010. "Serum Vitamin D Concentrations are Related to Depression in Young Adult US Population: The Third National Health and Nutrition Examination Survey," International Archives of Medicine, 3(29): 1-8.

Gernand, Alison D., Hyagriv N. Simhan, Mark A. Klebanoff, and Lisa M. Bodnar. 2013. "Maternal Serum 25-Hydroxyvitamin D and Measures of Newborn and Placental Weight in a U.S. Multicenter Cohort Study," Journal of Clinical Endocrinology and Metabolism. 98(1): 398-404.

Ginde, Adit A, Mark Liu, and Carlos Carmago. 2009. "Demographic Differences and Trends of Vitamin D Insufficiency in the US Population, 1988-2004," Archives of Internal Medicine. 169(6): 626-632.

Ginde, Adit A; Ashley F. Sullivan, Jonathan M. Mansbach, and Carlos A. Jr. Camargo. 2010. "Vitamin D Insufficiency in Pregnant and Nonpregnant Women of Childbearing Age in the United States," American Journal of Obstetrics and Gynecology, 202(5): 436.e1-8.

Godar, Dianne Eyvonn, Stanley James Pope, William Burgess Grant, and Michael Francis Holick. 2012. "Solar UV Doses of Young Americans and Vitamin D3 Production," Environmental Health Perspectives, 120(1): 139-43. 
Godar, Dianne E., Steven P. Wengraitis, Jack Shreffler, and David H. Sliney. 2001. "UV Doses of Americans," Photochemistry and Photobiology, 73(6): 621-29.

Goldenberg, Robert L., Suzanne P. Cliver, Francis X. Mulvihill, Carol A. Hickey, Howard J. Hoffman, Lorraine V. Klerman, and Marilyn J. Johnson. 1996. "Medical, psychosocial, and behavioural risk factors do not explain the increased risk for low birth weight among black women," American Journal of Obstetrics and Gynecology, 175(5): 1317-1324.

Grayson, Rebekah and Martin Hewison. 2011. "Vitamin D and Human Pregnancy," Fetal and Maternal Medicine Review. 22(1): 67-90.

Harris, Susan S. and Bess Dawson-Hughes. 1998. "Seasonal Changes in Plasma 25hydroxyvitamin D concentrations of young American black and white women," American Journal of Clinical Nutrition. 67(6): 1232-6.

Holick, Michael F. 2002. "Too little vitamin D in pre-menopausal women: why should we care?," American Journal of Clinical Nutrition. 76: 3-4.

Holick, Michael F. 2007. "Vitamin D Deficiency," New England Journal of Medicine. 357(3): 266-281.

Hollis, Bruce W., Donna Johnson, Thomas C. Hulsey, Myla Ebeling, and Carol L. Wagner. 2011. "Vitamin D Supplementation during Pregnancy: Double Blind, Randomized Clinical Trial of Safety and Effectiveness," Journal of Bone and Mineral Research. 26(10): 2341-57.

Howards, Penelope P., Irva Hertz-Picciotto, Clarice R. Weinberg, and Charles Poole. 2006. "Missclassification of Gestational Age in the Study of Spontaneous Abortion," American Journal of Epidemiology, 164 (11): 1126-1136.

Hoynes, Hilary, Marianne Page, and Ann Huff Stevens. 2011. "Can Targeted Transfers Improve Birth Outcomes? Evidence from the Introduction of the WIC Program," Journal of Public Economics, 96: 813-827.

Health Physics Society (HPS). 2009. "Pregnancy and Radiation Exposure." (http://hps.org/publicinformation/ate/faqs/pregnancyandradiationexposure.html).

Humble, Mats B. 2010. "Vitamin D, Light and Mental Health," Journal of Photochemistry and Photobiology. 101(2): 142-9.

Jablonski, Nina J. 2004. "The Evolution of Human Skin and Skin Color." Annual. Review of Anthropology. 33:585-623.

Kestenbaum, Bert. 1987. "Two Findings from the Decennial Census," Social Biology. 34: 24448. 
Knittel, Christopher R., Douglas L. Miller, and Nicholas J. Sanders. 2011. “Caution, Drivers! Children Present: Traffic, Pollution and Infant Health,” NBER Working Paper \#17222.

Kogan, Michael D., Greg R. Alexander, Milton Kotelchuck, and David A. Nagey. 1994. "Relation of the Content of Prenatal Care to the Risk of Low Birth Weight: Maternal Reports of Health Behavior Advice and Initial Prenatal Care Procedures," Journal of the American Medical Association. 271(17): 1340-1345.

Lapillonne, Alexandre. 2010. "Vitamin D Deficiency during Pregnancy May Impair Maternal and Fetal Outcomes," Medical Hypotheses, 74: 71-75.

Lewis, Sharon, Robyn M. Lucas, Jane Halliday, and Anne-Louise Ponsonby. 2010. "Vitamin D Deficiency and Pregnancy: From Preconception to Birth," Molecular Nutrition and Food Research. 54: 1092-1102.

Lhila, Aparna and Sharon Long. 2012. "What is Driving the Black-White Difference in Low Birthweight in the US?" Health Economics, 21: 301-315. (http://onlinelibrary.wiley.com/doi/10.1002/hec.1715/pdf).

Lokshin, Michael and Sergiy Radyakin. 2012. "Month of Birth and Children's Health in India," Journal of Human Resources. 47(1): 174-203.

Looker, Anne C., Clifford L. Johnson, David A. Lacher, Christine M. Pfeiffer, Rosemary L. Schleicher, and Christopher T. Sempos. 2011. "Vitamin D Status: United States, 20012006," NCHS Data Brief. No. 59.

Mannion, Cynthia A., Katherine Gray-Donald, and Kristine G. Koski. 2006. "Association of low intake of mile and vitamin D during pregnancy with decreased birth weight," Canadian Medical Association Journal. 174(9): Online-1-5.

Mulligan, Megan L., Shalil K. Felton, Amy E. Riek, and Carlos Bernal-Mizrachi. 2010. "Implications of Vitamin D Deficiency in Pregnancy and Lactation," American Journal of Obstetrics and Gynecology. 202: 429.e1-e9.

Murray L.J., D.P.J. O'Reilly, N. Betts, C.C. Patterson, G.D. Smith, and A.E. Evans. 2000. "Season and Outdoor Ambient Temperature: Effects on Birth Weight," Obstetrics and Gynecology. 96(5): 689-695.

Narchi, H, et al. 2010. "Maternal Vitamin D Status Throughout and After Pregnancy," Journal of Obstetrics and Gynecology. 30(20): 137-142.

NASA Atmospheric Science Data Center. 2010. "Meteorology and Solar Energy: Daily Data (1983-2006)."

National Center for Health Statistics. 2010. "Natality Detail Files 1989-2004 (Public Use)." 
Nesby-O'Dell, Shanna; Kelley S Scanlon, Mary E Cogswell, Cathleen Gillespie, Bruce W Hollis, Anne C Looker, Chris Allen, Cindy Doughertly, Elaine W Gunter, and Barbara A Bowman. 2002. "Hypovitaminosis D Prevalence and Determinants among African American and White Women of Reproductive Age: Third National Health and Nutrition Examination Survey, 1988-1994," American Journal of Clinical Nutrition. 76: 187-92.

Norval, Mary. 2011. "The Challenges of UV-Induced Immunomodulation for Children's Health," Progress in Biophysics and Molecular Biology. 107(3): 323-332.

Norval, Mary and Gary M. Halliday. 2011. "The Consequences of UV-Induced Immunosuppression for Human Health," Photochemistry and Photobiology. 87(5): 965977.

Norval, Mary and Gregory M. Woods. 2011. "UV-Induced Immunosuppression and the Efficacy of Vaccination," Photochemical and Photobiological Sciences. 10(8): 1267-1274.

Oken, Emily, Ken P. Kleinman, Janet Rich-Edwards and Matthew W. Gillman. 2003. "A nearly continuous measure of birth weight for gestational age using a United States national reference," BMC Pediatrics. 3(1): 1-10.

Olsen, Irene E., Sue A. Groveman, M. Louise Lawson, Reese H. Clark and Babette S. Zemel. 2010. "New Intrauterine Growth Curves Based on United States Data," Pediatrics. 125: e214-224.

Parisi, Alfio V., Lennox R. Meldrum, Michael G. Kimlin, Joe C. Wong, Joanne F. Aiken, and Julie S. Mainstone. 2000. "Evaluation of differences in ultraviolet exposure during weekend and weekday activities," Physics in Medicine and Biology. 45(8): 2253-62.

Persson, Petra and Maya Rossin-Slater. 2014. "Family Ruptures, Stress, and the Mental Health of the Next Generation," Working Paper (http://web.stanford.edu/ perssonp/Persson_RossinSlater.pdf; Accessed 1/20/2015)

Ponsoby, Anne-Louise, Robyn M. Lucas, Sharon lewis, and Jane Halliday. 2010. "Vitamin D status during pregnancy and aspects of offspring health," Nutrients. 2: 389-407.

Premkumar, M., T. Sable, D. Dhanwal, and R. Dewan. 2013. "Vitamin D Homeostasis, Bone Mineral Metabolism, and Seasonal Affective Disorder during 1 Year of Antarctic Residence," Archives of Osteoporosis. 8(129): 1-10.

Rajakumar, Kumaravel and Stephen B. Thomas. 2005. "Reemerging Nutritional Rickets: A Historical Perspective," Archives of Pediatric Adolescent Medicine. 159.

Reusch, J; H. Ackermann, and K. Badenhoop. 2009. "Cyclic Changes of Vitamin D and PTH are Primarily Regulated by Solar Radiation: 5-Year Analysis of a German (50 degrees N) Population," Hormone and Metabolic Research. 41(5): 402-7. 
Rosenzweig, Mark R., and T. Paul Schultz. 1982. "The behavior of mothers as inputs to child health: The determinants of birth weight, gestation, and rate of fetal growth," Economic Aspects of Health, edited by Victor R. Fuchs. Chicago: University of Chicago Press, 5385.

Sayers, Adrian, Kate Tilling, Barbara J. Boucher, Kate Noonan, and Jon H. Tobias. 2009. "Predicting Ambient Ultraviolet from Routine Meteorological Data; Its Potential Use as an Instrumental Variable for Vitamin D Status in Pregnancy in a Longitudinal Birth Cohort in the UK," International Journal of Epidemiology. 1-8.

Scholl, Theresa O. and Xinhua Chen. 2009. "Vitamin D Intake During Pregnancy: Association with Maternal Characteristics and Infant Birth Weight," Early Human Development. 85: 231-4.

Scholl, Theresa O. and William G. Johnson. 2000. "Folic Acid: Influence on the Outcome of Pregnancy," American Journal of Clinical Nutrition. 71(5): 1295s-1303s.

Siikamäki, Juha. 2009. "Use of Time for Outdoor Recreation in the United States, 1965-2007," Resources for the Future Background Study, RFF DP 09-18. (http://www.rff.org/documents/RFF-DP-09-18.pdf; Accessed 7/4/13)

Simeonova, Emilia. 2011. "Out of Sight, Out of Mind? Natural Disasters and Pregnancy Outcomes in the USA,” CESifo Economic Studies. 57(3): 403-31.

Smith, Gordon C.S., Malcolm F.S. Smith, Margaret B. McNay, and John E.E. Fleming. 1998. "First-Trimester Growth and the Risk of Low Birth Weight," The New England Journal of Medicine. 339:1817-1822.

Swamy, Geeta K., Melanie E. Garrett, Marie Lynn Miranda, and Allison E. Ashley-Koch. 2011. "Maternal Vitamin D Receptor Genetic Variation Contributes to Infant Birthweight among Black Mothers," American Journal of Medical Genetics. 1264-71.

Terushkin, Vitaly; Anna Bender, Estee L. Psaty, Ola Engelsen, Steven Q. Wang, and Allan C. Halpern. 2010. "Estimated Equivalency of Vitamin D Production from Natural Sun Exposure versus Oral Vitamin D Supplementation across Seasons at Two US Latitudes," Journal of the American Academy of Dermatology. 62(6): 929.e1-9

Tustin, Karen, Julien Gross and Harlene Hayne. 2004. "Maternal Exposure to First-Trimester Sunshine is Associated with Increase Birth Weight in Human Infants," Developmental Psychobiology. 45:221-230.

Vieth, Reinhold. 2007. "Vitamin D Toxicity, Policy, and Science," Journal of Bone and Mineral Research. 22(S2): V64-V68.

Wagner, Carol L.; Rebecca McNeil, Stuart A. Hamilton, Joyce Winkler, Carolina Rodriguez Cook, Gloria Warner, Betty Bivens, Deborah J. Davis, Pamela G. Smith, Martha Murphy, 
Judy R. Shary, and Bruce W. Hollis. 2013. "A randomized trial of vitamin D supplementation in 2 community health center networks in South Carolina," American Journal of Obstetrics and Gynecology, 208(2): 137.e1.

Webb, Ann and Ola Engelsen. 2006. "Calculated Ultraviolet Exposure Levels for a Healthy Vitamin D Status," Photochemistry and Photobiology. 82:1697-1703.

Wernerfelt, Nils; David Slusky, and Richard Zeckhauser. 2014. "Second Trimester Sunlight and Asthma: Evidence from Two Independent Studies,” NBER Working Paper \# 20599.

Wolpowitz, Deon and Barbara A. Gilchrest. 2006. "The vitamin D questions: How much do you need and how should you get it?" Journal of the American Academy of Dermatology. 54(2): 301-317.

Yu, C.K. H., L. Sykes, M. Sethit, T.G. Teoh, and S. Robinson. 2009. "Vitamin D Deficiency and Supplementation during Pregnancy," Clinical Endocrinology. 70(5): 685-90.

Zivin, Joshua Graff and Matthew J. Neidell. 2010. "Temperature and the Allocation of Time: Implications for Climate Change,” NBER Working Paper \#15717. 
Figure 1. The estimated effects of insolation on birth weight from the full pregnancy models, by race

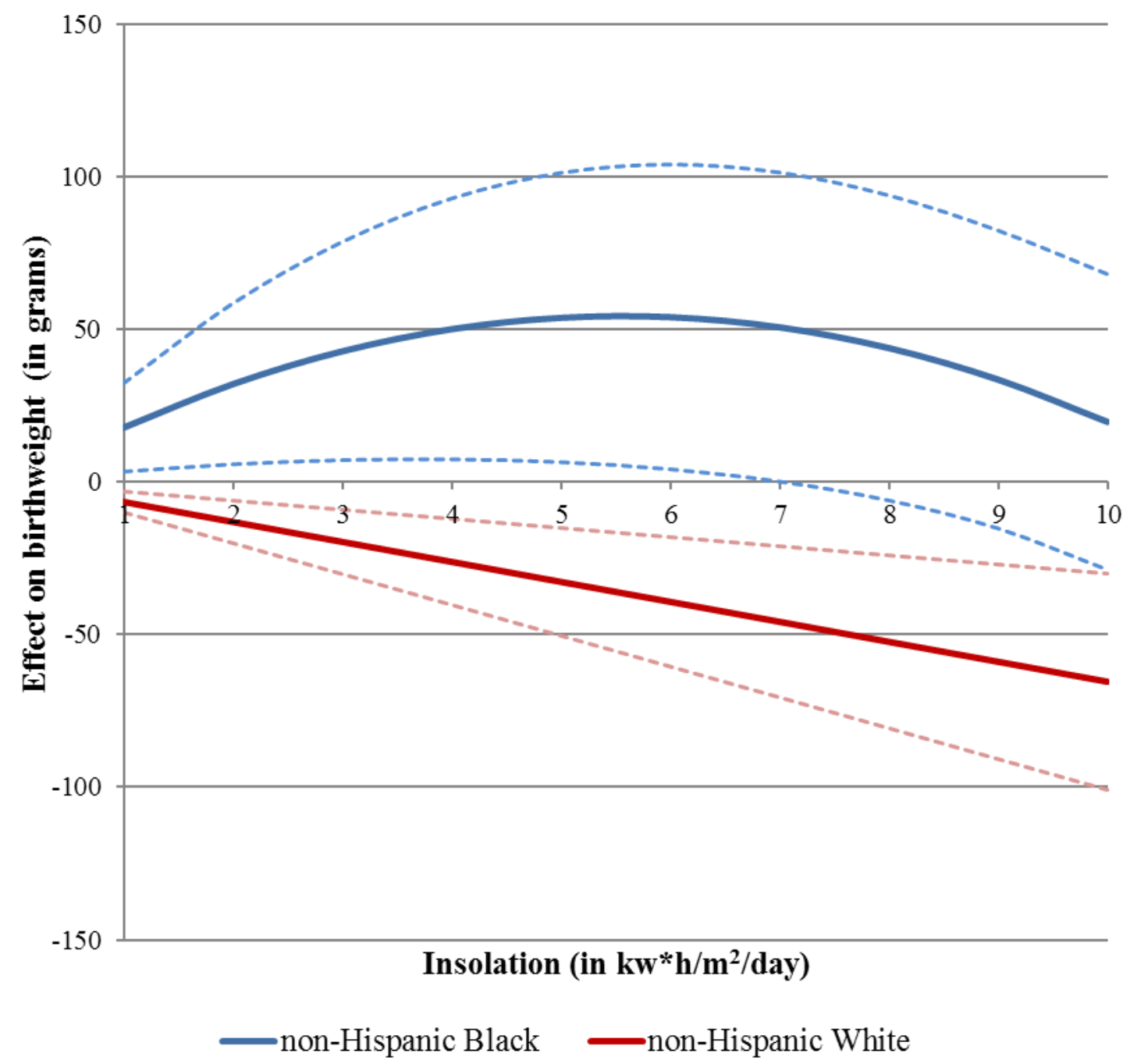

Note: The plots are based on estimates reported in the first row of Table 2, which requires a linear effect for Whites. For results allowing a quadratic effect, see Figure A.3. For each sample, the full pregnancy insolation measure ranges from 2.54 to 6.62. The dotted lines reflect the $95 \%$ confidence interval for the estimated effects. 
Figure 2. The estimated effects of insolation on birth weight from the trimester models, by race

a. NonHispanic Blacks

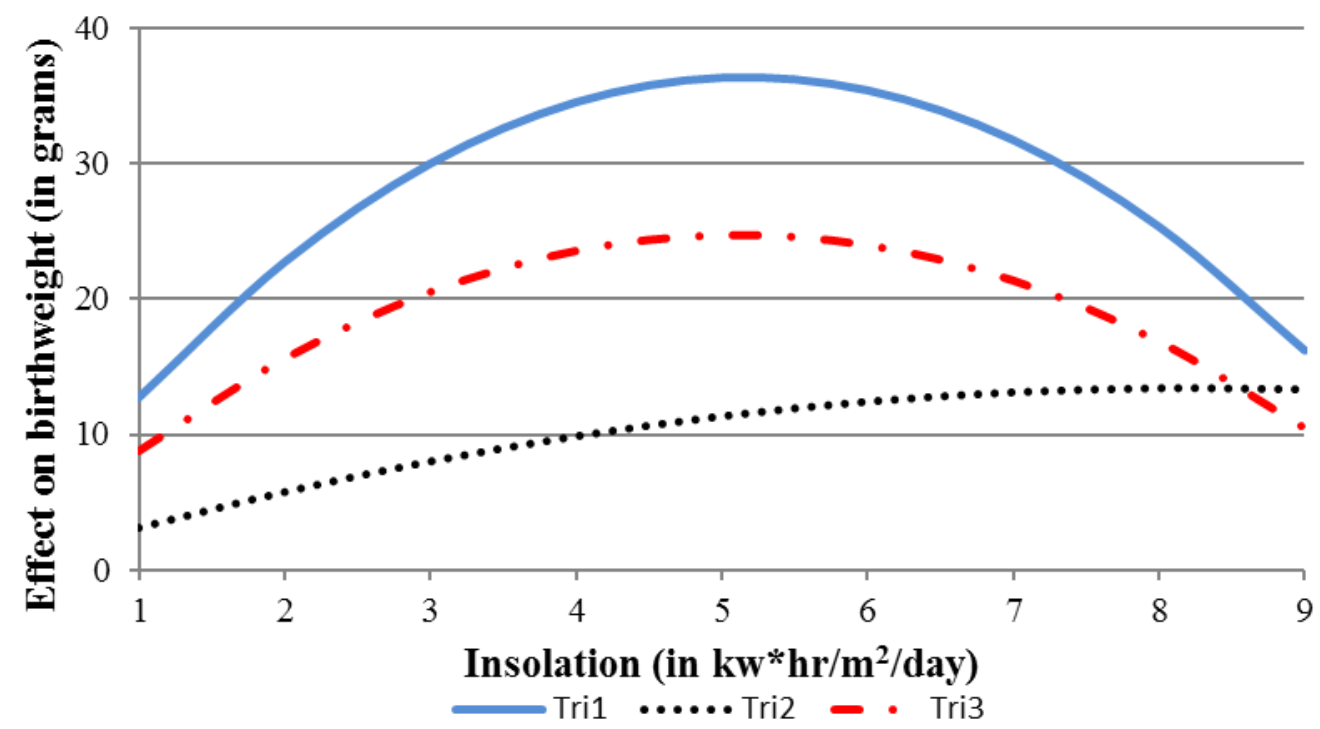

b. NonHispanic Whites

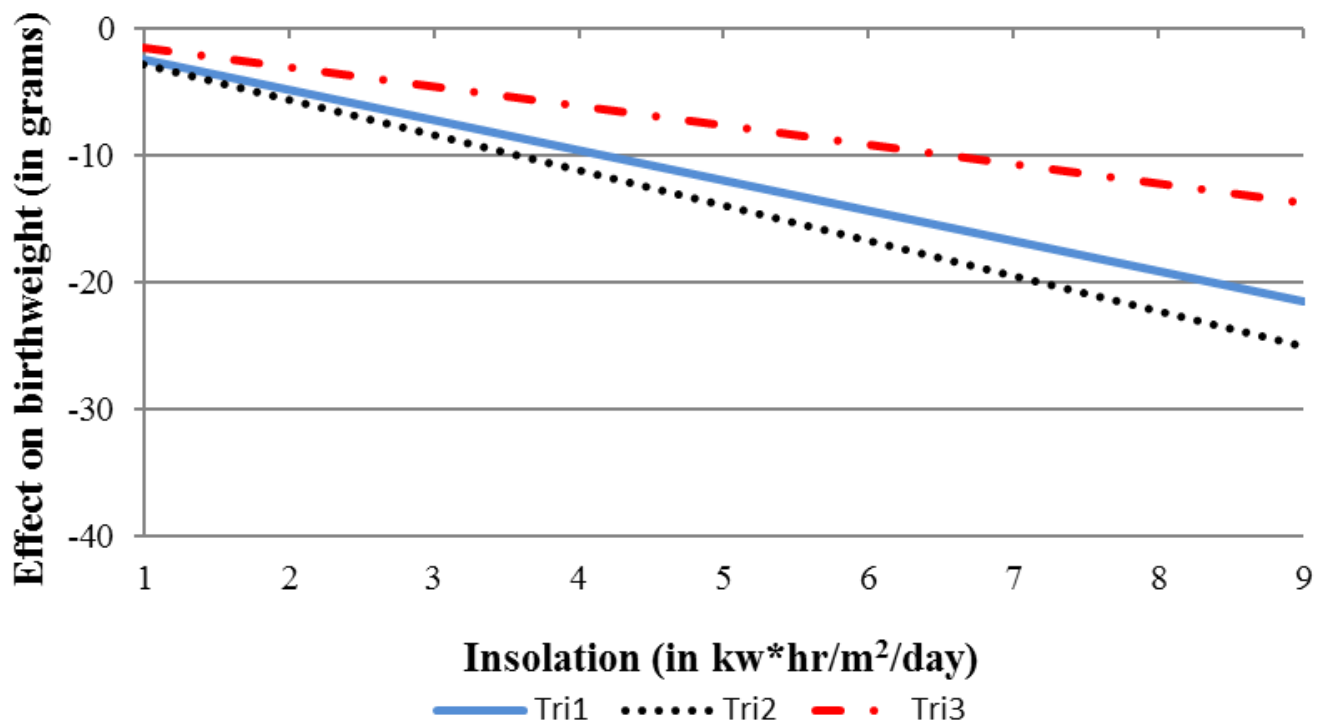

Note: The plots are based on the 'by trimester' estimates reported in Table 2, which requires a linear effect for Whites. For results allowing a quadratic effect, see Figure A.4. For each sample the trimester measures range from .84 to 8.55. 
Table 1. Distribution of sample insolation measures (in deciles)

\begin{tabular}{|c|c|c|c|c|c|c|c|c|c|c|}
\hline & $1 \mathrm{st}$ & 2nd & $3 \mathrm{rd}$ & 4th & 5 th & 6 th & 7th & 8th & 9th & 10th \\
\hline \multicolumn{11}{|c|}{ Weather over sample period $(1989-2004) \dagger$} \\
\hline Daily & 0.9 & 1.7 & 2.4 & 3.0 & 3.7 & 4.4 & 5.1 & 5.9 & 6.7 & 7.9 \\
\hline \multicolumn{11}{|c|}{ Weather observed for sample population } \\
\hline Monthly & 1.6 & 2.2 & 2.8 & 3.4 & 4.0 & 4.5 & 5.0 & 5.5 & 6 & 6.8 \\
\hline Trimester & 1.8 & 2.4 & 2.9 & 3.5 & 4.0 & 4.5 & 5.0 & 5.4 & 5.7 & 6.5 \\
\hline Full Pregnancy & 3.1 & 3.4 & 3.7 & 3.9 & 4.1 & 4.2 & 4.4 & 4.6 & 4.9 & 5.5 \\
\hline
\end{tabular}

White - Black mean birth weight by full pregnancy insolation decile (in grams)

\begin{tabular}{c|c|c|c|c|c|c|c|c|c}
237.5 & 222.3 & 220.8 & 215.2 & 214.7 & 216.1 & 213.1 & 207.4 & 200.5 & 194.5 \\
\hline \multicolumn{3}{c|}{$1^{\text {st }}$ to $5^{\text {th }}$ decile: 22.8} & \multicolumn{5}{c}{$5^{\text {th }}$ to 10 th decile: 20.2} \\
\hline
\end{tabular}

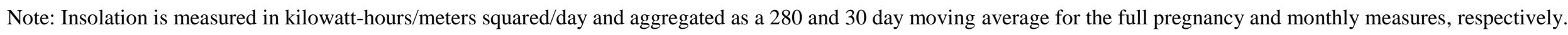
$\dagger$ Daily insolation decile measures reflect the actual distribution of weather across all sample counties for 1989-2004. It is an unweighted weather measure.

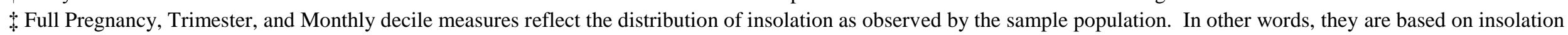
during pregnancy as calculated for our NDF sample. 
Table 2. Estimated birth weight effects for full pregnancy, by trimester and by month

\begin{tabular}{|c|c|c|c|c|c|c|c|c|}
\hline & & & NonHispar & c Blacks & & & NonHispa & c Whites \\
\hline & Insol & Insol Sq. & $\begin{array}{c}\text { Marginal } \\
\text { Effect }^{+}\end{array}$ & Temp & Temp Sq. & $\begin{array}{l}\text { Marginal } \\
\text { Effect }^{+}\end{array}$ & Insol & Temp \\
\hline Full Pregna & & & & & & & & \\
\hline Total & $\begin{array}{c}19.595^{* *} \\
(8.046) \\
\end{array}$ & $\begin{array}{c}-1.762 * * \\
(0.691) \\
\end{array}$ & 4.879 & $\begin{array}{c}-2.302 * * * \\
(0.767)\end{array}$ & $\begin{array}{c}0.010 \\
(0.006) \\
\end{array}$ & -0.999 & $\begin{array}{c}-6.541 * * * \\
(1.815)\end{array}$ & $\begin{array}{l}-0.270 \\
(0.200) \\
\end{array}$ \\
\hline Joint Test & 3.2 & $k * *$ & & 7.0 & $* * *$ & & & \\
\hline By Trimest & & & & & & & & \\
\hline First & $\begin{array}{c}14.129 * * * \\
(2.598)\end{array}$ & $\begin{array}{c}-1.369 * * * \\
(0.223)\end{array}$ & 2.678 & $\begin{array}{l}-0.565^{*} \\
(0.334)\end{array}$ & $\begin{array}{c}0.002 \\
(0.003)\end{array}$ & -0.282 & $\begin{array}{c}-2.395 * * * \\
(0.753)\end{array}$ & $\begin{array}{l}-0.075 \\
(0.119) \\
\end{array}$ \\
\hline Second & $\begin{array}{c}3.241 \\
(3.903)\end{array}$ & $\begin{array}{l}-0.196 \\
(0.333) \\
\end{array}$ & 1.606 & $\begin{array}{c}-0.741 * * \\
(0.285)\end{array}$ & $\begin{array}{c}0.005^{* *} * \\
(0.002)\end{array}$ & -0.085 & $\begin{array}{c}-2.779 * * * \\
(1.012)\end{array}$ & $\begin{array}{l}-0.065 \\
(0.109) \\
\end{array}$ \\
\hline Third & $\begin{array}{c}9.658 * * * \\
(3.222)\end{array}$ & $\begin{array}{c}-0.945 * * * \\
(0.317)\end{array}$ & 1.771 & $\begin{array}{l}-0.556 \\
(0.395) \\
\end{array}$ & $\begin{array}{c}0.001 \\
(0.003)\end{array}$ & -0.408 & $\begin{array}{l}-1.530^{*} \\
(0.875)\end{array}$ & $\begin{array}{l}-0.106 \\
(0.094)\end{array}$ \\
\hline Joint Test & 7.4 & $k * *$ & & & & & $4.60 * * *$ & 0.83 \\
\hline By Month & & & & & & & & \\
\hline First & $\begin{array}{c}1.504 \\
(2.059) \\
\end{array}$ & $\begin{array}{l}-0.069 \\
(0.226) \\
\end{array}$ & 0.923 & $\begin{array}{c}0.218 \\
(0.183) \\
\end{array}$ & $\begin{array}{l}-0.001 \\
(0.002) \\
\end{array}$ & 0.083 & $\begin{array}{l}-1.090^{*} \\
(0.572) \\
\end{array}$ & $\begin{array}{c}0.118^{* *} \\
(0.052) \\
\end{array}$ \\
\hline Second & $\begin{array}{l}5.069^{* *} \\
(2.071) \\
\end{array}$ & $\begin{array}{c}-0.530 * * \\
(0.242)\end{array}$ & 0.633 & $\begin{array}{l}-0.035 \\
(0.270) \\
\end{array}$ & $\begin{array}{l}-0.001 \\
(0.003) \\
\end{array}$ & -0.195 & $\begin{array}{c}-0.001 \\
(0.585) \\
\end{array}$ & $\begin{array}{l}-0.122 * \\
(0.069) \\
\end{array}$ \\
\hline Third & $\begin{array}{l}3.620^{*} \\
(1.926)\end{array}$ & $\begin{array}{r}-0.259 \\
(0.171) \\
\end{array}$ & 1.455 & $\begin{array}{l}-0.142 \\
(0.225) \\
\end{array}$ & $\begin{array}{c}0.000002 \\
(0.002)\end{array}$ & -0.142 & $\begin{array}{c}-1.180 * * \\
(0.536) \\
\end{array}$ & $\begin{array}{l}-0.069 \\
(0.076)\end{array}$ \\
\hline Fourth & $\begin{array}{c}1.498 \\
(2.400) \\
\end{array}$ & $\begin{array}{l}-0.184 \\
(0.230) \\
\end{array}$ & -0.035 & $\begin{array}{c}0.026 \\
(0.234) \\
\end{array}$ & $\begin{array}{l}0.0002 \\
(0.002) \\
\end{array}$ & 0.046 & $\begin{array}{l}-1.104^{*} \\
(0.621) \\
\end{array}$ & $\begin{array}{l}-0.019 \\
(0.059) \\
\end{array}$ \\
\hline Fifth & $\begin{array}{c}2.543 \\
(2.312) \\
\end{array}$ & $\begin{array}{l}-0.175 \\
(0.210) \\
\end{array}$ & 1.080 & $\begin{array}{l}-0.208 \\
(0.199) \\
\end{array}$ & $\begin{array}{c}0.001 \\
(0.002) \\
\end{array}$ & -0.096 & $\begin{array}{c}-1.425^{* *} \\
(0.584) \\
\end{array}$ & $\begin{array}{c}0.107 \\
(0.081) \\
\end{array}$ \\
\hline Sixth & $\begin{array}{l}-0.925 \\
(2.133) \\
\end{array}$ & $\begin{array}{c}0.259 \\
(0.195) \\
\end{array}$ & 1.237 & $\begin{array}{c}0.078 \\
(0.180) \\
\end{array}$ & $\begin{array}{l}-0.001 \\
(0.002) \\
\end{array}$ & -0.055 & $\begin{array}{l}-0.149 \\
(0.542) \\
\end{array}$ & $\begin{array}{l}-0.106^{* * *} \\
(0.053) \\
\end{array}$ \\
\hline Seventh & $\begin{array}{l}3.509^{*} \\
(1.826) \\
\end{array}$ & $\begin{array}{c}-0.394 * * \\
(0.151)\end{array}$ & 0.225 & $\begin{array}{l}-0.386^{*} \\
(0.230) \\
\end{array}$ & $\begin{array}{c}0.003 \\
(0.002) \\
\end{array}$ & 0.061 & $\begin{array}{l}-0.540 \\
(0.532) \\
\end{array}$ & $\begin{array}{l}-0.017 \\
(0.049) \\
\end{array}$ \\
\hline Eighth & $\begin{array}{c}0.920 \\
(1.988) \\
\end{array}$ & $\begin{array}{c}-0.076 \\
(0.253) \\
\end{array}$ & 0.287 & $\begin{array}{l}-0.149 \\
(0.271) \\
\end{array}$ & $\begin{array}{c}0.001 \\
(0.002)\end{array}$ & -0.084 & $\begin{array}{l}-0.653 \\
(0.511) \\
\end{array}$ & $\begin{array}{l}-0.013 \\
(0.065) \\
\end{array}$ \\
\hline Ninth & $\begin{array}{c}2.615 \\
(1.805) \\
\end{array}$ & $\begin{array}{l}-0.230 \\
(0.230) \\
\end{array}$ & 0.694 & $\begin{array}{l}0.447^{*} \\
(0.224) \\
\end{array}$ & $\begin{array}{c}-0.006^{* * *} * \\
(0.002)\end{array}$ & -0.384 & $\begin{array}{l}-0.584 \\
(0.692) \\
\end{array}$ & $\begin{array}{l}-0.021 \\
(0.070) \\
\end{array}$ \\
\hline Joint Test & 3.9 & & & & **** & & $3.84 * *$ & $3.27 * *$ \\
\hline
\end{tabular}

Notes: Robust standard errors adjusted for clustering at the state level are reported in the parentheses. *, **, and *** denote statistical significance at 10, 5, and $1 \%$ levels, respectively. Each model includes indicators of maternal age, education, marital status, parity, and infant gender, as well as insolation and temperature expected at birth, and month and county*year fixed effects.

Joint tests of trimester models incorporate all 3 (6) insolation/temperature measures for the White linear (Black nonlinear) specification, and 9 (18) for the monthly models. They are reported as F-statistics in italics.

${ }^{+}$Marginal effects are evaluated at the sample mean values of insolation and temperature. 
Table 3. Estimated birth weight effects by weekend/weekday

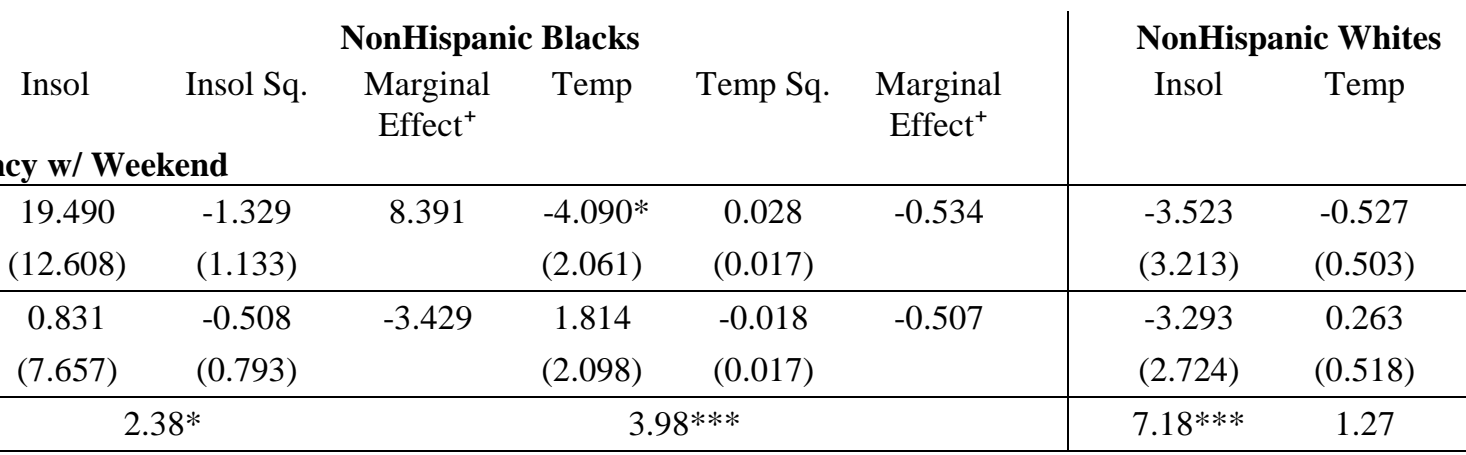

\section{By Trimester \& Weekend}

\begin{tabular}{|c|c|c|c|c|c|c|c|c|}
\hline First & $\begin{array}{c}13.599 * * \\
(5.390)\end{array}$ & $\begin{array}{c}-1.145^{* *} \\
(0.559)\end{array}$ & 4.025 & $\begin{array}{c}-0.315 \\
(1.123)\end{array}$ & $\begin{array}{c}0.000003 \\
(0.009)\end{array}$ & -0.315 & $\begin{array}{l}-1.251 \\
(1.643)\end{array}$ & $\begin{array}{c}0.175 \\
(0.243)\end{array}$ \\
\hline *Wknd & $\begin{array}{c}0.927 \\
(4.563)\end{array}$ & $\begin{array}{l}-0.279 \\
(0.484)\end{array}$ & -1.415 & $\begin{array}{l}-0.257 \\
(1.048)\end{array}$ & $\begin{array}{c}0.002 \\
(0.009)\end{array}$ & 0.018 & $\begin{array}{l}-1.263 \\
(1.193)\end{array}$ & $\begin{array}{l}-0.260 \\
(0.237)\end{array}$ \\
\hline Second & $\begin{array}{c}5.390 \\
(4.389)\end{array}$ & $\begin{array}{c}-0.321 \\
(0.441)\end{array}$ & 2.711 & $\begin{array}{l}-0.011 \\
(0.733)\end{array}$ & $\begin{array}{c}0.001 \\
(0.006)\end{array}$ & 0.153 & $\begin{array}{l}-1.679 \\
(1.414)\end{array}$ & $\begin{array}{l}-0.325^{*} \\
(0.165)\end{array}$ \\
\hline *Wknd & $\begin{array}{l}-2.138 \\
(3.848) \\
\end{array}$ & $\begin{array}{c}0.109 \\
(0.436)\end{array}$ & -1.221 & $\begin{array}{l}-0.825 \\
(0.652)\end{array}$ & $\begin{array}{c}0.004 \\
(0.006) \\
\end{array}$ & -0.260 & $\begin{array}{l}-1.262 \\
(1.144) \\
\end{array}$ & $\begin{array}{c}0.255 \\
(0.168) \\
\end{array}$ \\
\hline Third & $\begin{array}{c}8.191 \\
(5.365)\end{array}$ & $\begin{array}{l}-0.736 \\
(0.563)\end{array}$ & 2.047 & $\begin{array}{l}-2.328^{*} \\
(1.170)\end{array}$ & $\begin{array}{c}0.016 \\
(0.010)\end{array}$ & -0.226 & $\begin{array}{l}-0.634 \\
(1.426)\end{array}$ & $\begin{array}{l}-0.156 \\
(0.207)\end{array}$ \\
\hline *Wknd & $\begin{array}{c}1.589 \\
(3.806) \\
\end{array}$ & $\begin{array}{l}-0.219 \\
(0.418)\end{array}$ & -0.251 & $\begin{array}{l}1.816^{*} \\
(1.001)\end{array}$ & $\begin{array}{l}-0.016 * \\
(0.008)\end{array}$ & -0.176 & $\begin{array}{l}-0.988 \\
(1.201) \\
\end{array}$ & $\begin{array}{c}0.051 \\
(0.184) \\
\end{array}$ \\
\hline Joint Test & 8.3 & & & 4.7 & $* * *$ & & $3.76^{* * * *}$ & 1.57 \\
\hline
\end{tabular}

Notes: Robust standard errors adjusted for clustering at the state level are reported in the parentheses. ${ }^{*}, * *$, and ${ }^{* * *}$ denote statistical significance at 10,5, and $1 \%$ levels, respectively. Each model includes indicators of maternal age, education, marital status, parity, and infant gender, as well as insolation and temperature expected at birth, and month and county*year fixed effects.

Joint tests of weekend insolation/temperature for full pregnancy incorporate the 2 (4) insolation/temperature and weekend interactions for the White linear (Black nonlinear) specification, and all 6 (12) coefficient estimates for the trimester models. They are reported as F-statistics in italics.

+ Marginal effects are evaluated at the sample mean values of insolation and temperature. For weekends, the differential effects are reported. 
Table 4. Estimated birth weight effects allowing for pollution

\section{A. Stratifying by level of pollution}

\begin{tabular}{|c|c|c|c|c|c|c|c|c|}
\hline & \multicolumn{6}{|c|}{ NonHispanic Blacks } & \multicolumn{2}{|c|}{ NonHispanic Whites } \\
\hline & Insol & Insol Sq. & $\begin{array}{c}\text { Marginal } \\
\text { Effect }^{+}\end{array}$ & Temp & Temp Sq. & $\begin{array}{c}\text { Marginal } \\
\text { Effect }^{+}\end{array}$ & Insol & Temp \\
\hline Clean Counties & $\begin{array}{c}26.820 \\
(24.962) \\
\end{array}$ & $\begin{array}{l}-2.370 \\
(2.173) \\
\end{array}$ & 7.224 & $\begin{array}{l}-4.723 \\
(2.923) \\
\end{array}$ & $\begin{array}{c}0.033 \\
(0.028) \\
\end{array}$ & -0.666 & $\begin{array}{c}-11.775 * * \\
(5.742) \\
\end{array}$ & $\begin{array}{l}-0.097 \\
(0.425) \\
\end{array}$ \\
\hline Dirty Counties & $\begin{array}{c}9.187 \\
(13.450)\end{array}$ & $\begin{array}{l}-0.568 \\
(0.971) \\
\end{array}$ & 4.173 & $\begin{array}{l}-1.465 \\
(1.132) \\
\end{array}$ & $\begin{array}{c}0.004 \\
(0.010) \\
\end{array}$ & -0.944 & $\begin{array}{l}-0.612 \\
(4.081) \\
\end{array}$ & $\begin{array}{l}-0.136 \\
(0.471) \\
\end{array}$ \\
\hline
\end{tabular}

\section{B. Including a continuous measure of pollution (AQI)}

\begin{tabular}{|c|c|c|c|c|c|c|c|c|c|c|}
\hline & \multicolumn{7}{|c|}{ NonHispanic Blacks } & \multicolumn{3}{|c|}{ NonHispanic Whites } \\
\hline & Insol & Insol Sq. & $\begin{array}{c}\text { Marginal } \\
\text { Effect }^{+}\end{array}$ & Temp & $\begin{array}{l}\text { Temp } \\
\text { Sq. }\end{array}$ & $\begin{array}{l}\text { Marginal } \\
\text { Effect }^{+}\end{array}$ & AQI & Insol & Temp & AQI \\
\hline $\begin{array}{l}\text { Main Results (Table 2) } \\
\text { (all counties) }\end{array}$ & $\begin{array}{c}19.595 * * \\
(8.046)\end{array}$ & $\begin{array}{l}-1.762 * * \\
(0.691)\end{array}$ & 4.879 & $\begin{array}{c}-2.302 * * * \\
(0.767)\end{array}$ & $\begin{array}{c}0.010 \\
(0.006)\end{array}$ & -0.999 & & $\begin{array}{c}-6.541 * * * \\
(1.815)\end{array}$ & $\begin{array}{l}-0.270 \\
(0.200)\end{array}$ & \\
\hline $\begin{array}{l}\text { AQI Subset } \\
\text { (106 counties) }\end{array}$ & $\begin{array}{l}14.391 * \\
(7.224)\end{array}$ & $\begin{array}{l}-1.102 \\
(0.660)\end{array}$ & 4.916 & $\begin{array}{l}-2.305^{* *} \\
(0.985)\end{array}$ & $\begin{array}{c}0.012 \\
(0.008)\end{array}$ & -0.781 & & $\begin{array}{l}-8.950 * \\
(4.176)\end{array}$ & $\begin{array}{c}0.149 \\
(0.257)\end{array}$ & \\
\hline AQI Subset w/ AQI & $\begin{array}{l}14.485^{*} \\
(7.292)\end{array}$ & $\begin{array}{l}-1.109 \\
(0.659)\end{array}$ & 5.187 & $\begin{array}{l}-2.348 * * \\
(1.034)\end{array}$ & $\begin{array}{c}0.013 \\
(0.008)\end{array}$ & -0.715 & $\begin{array}{l}-0.018 \\
(0.130)\end{array}$ & $\begin{array}{l}-8.399 * * \\
(4.090)\end{array}$ & $\begin{array}{c}0.217 \\
(0.283)\end{array}$ & $\begin{array}{l}-0.119 \\
(0.071)\end{array}$ \\
\hline AQI Subset w/AQI Only & & & & & & & $\begin{array}{l}-0.017 \\
(0.091)\end{array}$ & & & $\begin{array}{c}-0.144 * * \\
(0.058)\end{array}$ \\
\hline
\end{tabular}

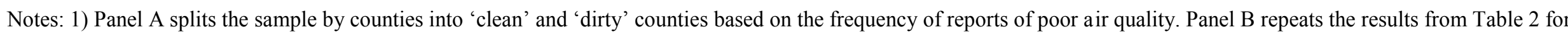
the full sample for comparison against models using the 106 counties for which daily pollution and weather data is available. 'AQI Subset' reports the estimated effects for those 106 counties. The last two models include a continuous air quality index (AQI) value aggregated to the county*month*year level.

2) Robust standard errors adjusted for clustering at the state level are reported in the parentheses. *,**, and *** denote statistical significance at 10,5 , and $1 \%$ levels, respectively. Each model includes indicators of maternal age, education, marital status, parity, and infant gender, as well as insolation and temperature expected at birth, and month and county*year fixed effects.

${ }^{+}$Marginal effects are evaluated at the sample mean values of insolation and temperature. 
Table 5. Stratifying by maternal characteristics and behaviors

\begin{tabular}{|c|c|c|c|c|c|c|c|c|}
\hline & \multicolumn{6}{|c|}{ NonHispanic Blacks } & \multicolumn{2}{|c|}{ NonHispanic Whites } \\
\hline & Insol & Insol Sq. & $\begin{array}{l}\text { Marginal } \\
\text { Effect }^{+}\end{array}$ & Temp & Temp Sq. & $\begin{array}{c}\text { Marginal } \\
\text { Effect }^{+}\end{array}$ & Insol & Temp \\
\hline Ages 19-27 Only & $\begin{array}{c}17.193 \\
(10.593)\end{array}$ & $\begin{array}{l}-1.339 \\
(0.931)\end{array}$ & 5.994 & $\begin{array}{c}-2.851 * * * \\
(0.773)\end{array}$ & $\begin{array}{c}0.013 * * \\
(0.006)\end{array}$ & -1.129 & $\begin{array}{c}-8.232 * * \\
(3.900)\end{array}$ & $\begin{array}{l}-0.418 \\
(0.321)\end{array}$ \\
\hline Ages 28-36 Only & $\begin{array}{c}22.561 \\
(13.706)\end{array}$ & $\begin{array}{c}-2.510 * * \\
(1.249)\end{array}$ & 1.549 & $\begin{array}{l}-1.231 \\
(1.101)\end{array}$ & $\begin{array}{c}0.004 \\
(0.009)\end{array}$ & -0.627 & $\begin{array}{c}-5.246 * * \\
(2.351)\end{array}$ & $\begin{array}{l}-0.293 \\
(0.259)\end{array}$ \\
\hline Ages 37-44 Only & $\begin{array}{c}31.860 \\
(22.255)\end{array}$ & $\begin{array}{l}-1.722 \\
(2.158)\end{array}$ & 17.382 & $\begin{array}{l}-2.144 \\
(2.965)\end{array}$ & $\begin{array}{c}0.003 \\
(0.025)\end{array}$ & -1.735 & $\begin{array}{l}-5.504 \\
(5.096)\end{array}$ & $\begin{array}{c}0.580 \\
(0.755)\end{array}$ \\
\hline Adequate Prenatal Care Use & $\begin{array}{c}22.636^{* * * *} \\
(7.162)\end{array}$ & $\begin{array}{c}-2.248 * * * \\
(0.681)\end{array}$ & 3.843 & $\begin{array}{c}-2.263 * * \\
(0.902)\end{array}$ & $\begin{array}{c}0.011 \\
(0.007)\end{array}$ & -0.809 & $\begin{array}{c}-6.945 * * * \\
(1.433)\end{array}$ & $\begin{array}{l}-0.306 \\
(0.220)\end{array}$ \\
\hline $\begin{array}{l}\text { Less than Adequate Prenatal } \\
\text { Care Use }\end{array}$ & $\begin{array}{c}4.308 \\
(14.425)\end{array}$ & $\begin{array}{c}0.196 \\
(1.204)\end{array}$ & 5.950 & $\begin{array}{l}-1.573 \\
(1.165)\end{array}$ & $\begin{array}{c}0.001 \\
(0.010)\end{array}$ & -1.514 & $\begin{array}{l}-2.478 \\
(6.707)\end{array}$ & $\begin{array}{l}-0.244 \\
(0.568)\end{array}$ \\
\hline Non-Smokers Only & $\begin{array}{l}11.388 \\
(8.146)\end{array}$ & $\begin{array}{l}-0.949 \\
(0.781)\end{array}$ & 3.554 & $\begin{array}{c}-2.388 * * * \\
(0.792)\end{array}$ & $\begin{array}{c}0.010 \\
(0.007)\end{array}$ & -1.071 & $\begin{array}{c}-8.054 * * * \\
(2.146)\end{array}$ & $\begin{array}{l}-0.137 \\
(0.255)\end{array}$ \\
\hline
\end{tabular}

Notes: Robust standard errors adjusted for clustering at the state level are reported in the parentheses. *, **, and *** denote statistical significance at 10,5 , and $1 \%$ levels, respectively. Each model includes indicators of maternal age, education, marital status, parity, and infant gender, as well as insolation and temperature expected at birth, and month and county*year fixed effects.

${ }^{+}$Marginal effects are evaluated at the sample mean values of insolation and temperature. 
Table 6. Estimated weather effects for alternative models of birth weight, full-term births (main sample)

\begin{tabular}{|c|c|c|c|c|c|c|c|c|}
\hline \multirow[b]{2}{*}{$\begin{array}{l}\text { Alternative covariates in the main model } \\
\text { (continuous measure of birth weight) }\end{array}$} & \multicolumn{6}{|c|}{ NonHispanic Blacks } & \multicolumn{2}{|c|}{ NonHispanic Whites } \\
\hline & Insol & Insol Sq. & $\begin{array}{l}\text { Marginal } \\
\text { Effect }^{+}\end{array}$ & Temp & Temp Sq. & $\begin{array}{l}\text { Marginal } \\
\text { Effect }^{+}\end{array}$ & Insol & Temp \\
\hline Main Results (Table 2) & $\begin{array}{c}19.595 * * \\
(8.046)\end{array}$ & $\begin{array}{l}-1.762 * * \\
(0.691)\end{array}$ & 4.879 & $\begin{array}{l}-2.302 * * * \\
(0.767)\end{array}$ & $\begin{array}{c}0.010 \\
(0.006)\end{array}$ & -0.999 & $\begin{array}{l}-6.541 * * * \\
(1.815)\end{array}$ & $\begin{array}{l}-0.270 \\
(0.200)\end{array}$ \\
\hline Exclude Maternal/Infant Characteristics & $\begin{array}{l}21.278 * * \\
(8.195)\end{array}$ & $\begin{array}{l}-1.815^{* *} \\
(0.708)\end{array}$ & 6.117 & $\begin{array}{l}-2.049 * * \\
(0.787)\end{array}$ & $\begin{array}{l}0.008 \ddagger \\
(0.006)\end{array}$ & -1.026 & $\begin{array}{c}-6.720 * * * \\
(1.764)\end{array}$ & $\begin{array}{l}-0.337 \\
(0.204)\end{array}$ \\
\hline Include Pre-Conception Weather ${ }^{\delta}$ & $\begin{array}{l}19.833 * * \\
(7.690)\end{array}$ & $\begin{array}{l}-1.824 * * \\
(0.692)\end{array}$ & 4.602 & $\begin{array}{l}-1.696 * \\
(0.827)\end{array}$ & $\begin{array}{c}0.008 \\
(0.006)\end{array}$ & -0.697 & $\begin{array}{l}-6.138 * * * \\
(2.289)\end{array}$ & $\begin{array}{l}-0.109 \\
(0.273)\end{array}$ \\
\hline
\end{tabular}

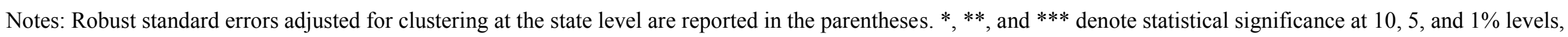

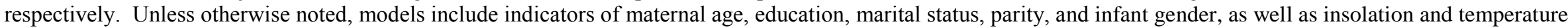
expected at birth, and month and county*year fixed effects.

${ }^{+}$Marginal effects are evaluated at the sample mean values of insolation and temperature.

${ }^{\delta}$ Includes average insolation and temperature in the two months prior to the month of conception. 
Table 7. Estimated weather effects for alternative measures of infant health, by trimester BROADER GESTATION SAMPLE (INCLUDES BIRTHS OF GESTATIONS 28-42 WEEKS)

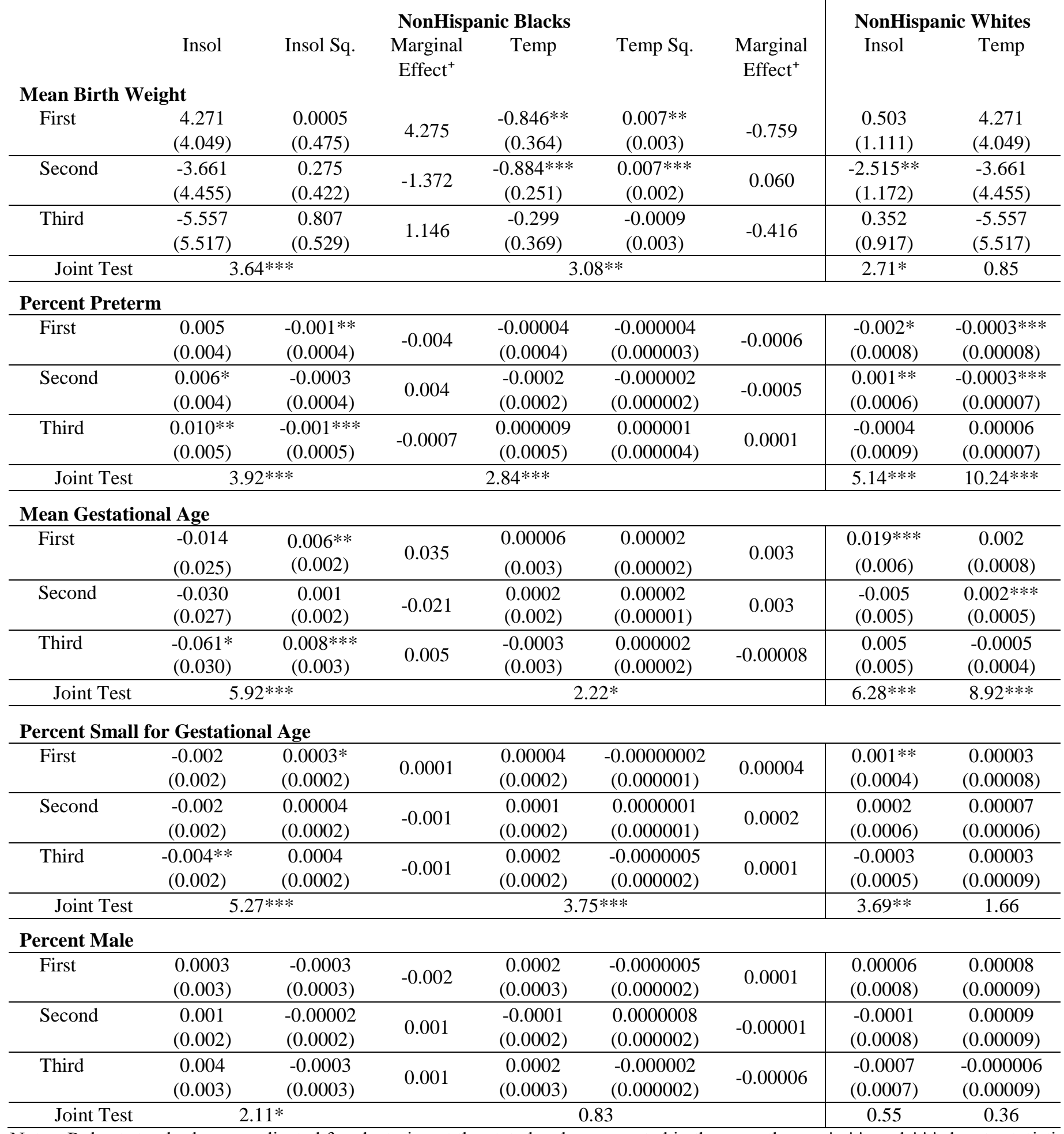

Notes: Robust standard errors adjusted for clustering at the state level are reported in the parentheses. $*, * *$, and $* * *$ denote statistical significance at 10,5, and 1\% levels, respectively. Each model includes indicators of maternal age, education, marital status, parity, and infant gender, as well as insolation and temperature expected at birth, and month and county*year fixed effects.

Joint tests of trimester models incorporate all 3 (6) insolation/temperature measures for the White linear (Black nonlinear) specification. They are reported as F-statistics in italics.

${ }^{+}$Marginal effects are evaluated at the sample mean values of insolation and temperature. 